ISSN 1112-9867

http://www.jfas.info

\title{
A STRATEGY TO IMPROVE THE QUALITY OF THE ELECTRIC POWER PRODUCED BY A WIND TURBINE UNDER VARIABLE SPEED USING A PROPORTIONAL RESONANT CONTROLLER
}

\author{
F. D. Menga ${ }^{1}$, N. Djongyang ${ }^{1, *}$, D. Raïdandi ${ }^{2}$, R. Tchinda ${ }^{3}$ and A. Zaatri ${ }^{4}$ \\ ${ }^{1}$ Department of Renewable Energy, The Higher Institute of the Sahel, University of Maroua, PO Box \\ 46 Maroua, Cameroon \\ ${ }^{2}$ Department of Material Processing, Architecture and Habitat, The Higher Institute of the Sahel, \\ University of Maroua, PO Box 46 Maroua, Cameroon \\ ${ }^{3}$ LISIE, Fotso Victor University Institute of Technology, University of Dschang, PO Box 146 \\ Bandjoun, Cameroon \\ ${ }^{4}$ Department of Mechanical Engineering, Faculty of Engineering Science, University of Constantine 1, \\ Cité Filali, Bat: F, No 2, 25000, Constantine, Algeria
}

Received: 24 Jully 2015 / Accepted: 02 December 2016 / Published online: 01 May 2016

\begin{abstract}
The wind power is well adapted nowadays as solution to the production of electricity or for mechanical use. But wind is a very fluctuating source of energy; it generates a non-permanent and variable power to the loads. This paper presents a strategy to improve the quality of the electric power produced by a wind turbine under variable speed. The mathematical modeling of the various elements of the conversion system is performed. Two control strategies are developed to improve the quality of the energy produced by the wind turbine. The first consists to a judicious management of the DC bus and the second to control the inverters with a corrective proportional resonant. The results obtained after implementation and simulation under Matlab/Simulink platform are presented.
\end{abstract}

Keywords: wind turbine; electric power quality; corrective proportional resonant; DC Bus.

Author Correspondence, e-mail: noeldjongyang@gmail.com doi: http://dx.doi.org/10.4314/jfas.v8i2.1 


\section{INTRODUCTION}

Wind is one of the cleanest sources of energy. During its transformation processes, it releases approximately $9 \mathrm{~g}$ of polluting substance per kilowatt-hour [1]. But, even if clean and inexhaustible, wind is very fluctuating. It generates a non-permanent and variable power to the loads. Most of the times, to ensure continuity of power to the loads, the wind turbine is either connected to a non-corporate/public network, other forms of electrical energy sources (solar, diesel generator, etc.), autonomous or hybrid networks [2,3].

If the permanence of the electrical energy produced by a wind turbine can be assured, its quality remains an important issue to be considered in the distribution network. Several authors investigated the problem using grid-connected or not wind turbines. Laverdure [4] made a comparative study of various wind turbine structures and impacts of disturbances on the integration of wind power generators in weak networks or remote area. Courtecuisse [5] presented strategies of controlling multi-source wind databases coupled to energy storage systems to ensure the stability of the network and optimize energy consumption. Vechui [6] proposed a solution to balance the voltage across the unbalanced load inverter when connecting energy from a renewable source into the conventional network. Camblong [7] worked on minimizing wind disturbances in the generation of electricity from wind turbines with variable speed. He developed algorithms to control variable wind speed turbine pitch control and to maximize aerodynamic efficiency and the quality of electric power in terms of flicker. He also showed the advantage of RST regulators compared to the traditional PI controllers in some commands. Davigny [8] investigated wind systems at variable speed equipped with permanent magnet synchronous generator (PMSG), and a system of inertial storage. He illustrated the capacities of the resonant controller in the direct control of the terminal voltages. Masmoudi et al. [9] used the model developed in [8], substituted the system of inertial storage by batteries of super-capacitors to show that the system reacts more quickly to fluctuations.

In the present work, we are investigating the quality of the electrical energy produced by a variable speed wind turbine using supercapacitors as short-term storage systems. The main objective is to improve the quality of the electrical energy produced by developing control strategies to manage the electric power at the DC bus and the output of the LC filter. 


\section{MODELING OF THE ENERGY CONVERSION SYSTEM}

The conversion system is presented in figure 1. It is made up of a wind turbine associated to a permanent magnet synchronous machine (PMSM) with a large number of pair of poles connected to an interface and a storage system via power converters controlled by a PWM (pulse width modulation) and a DC bus. The connection interface is made of an IGBT inverter and LC filter. The storage system is constituted of super-capacitors.

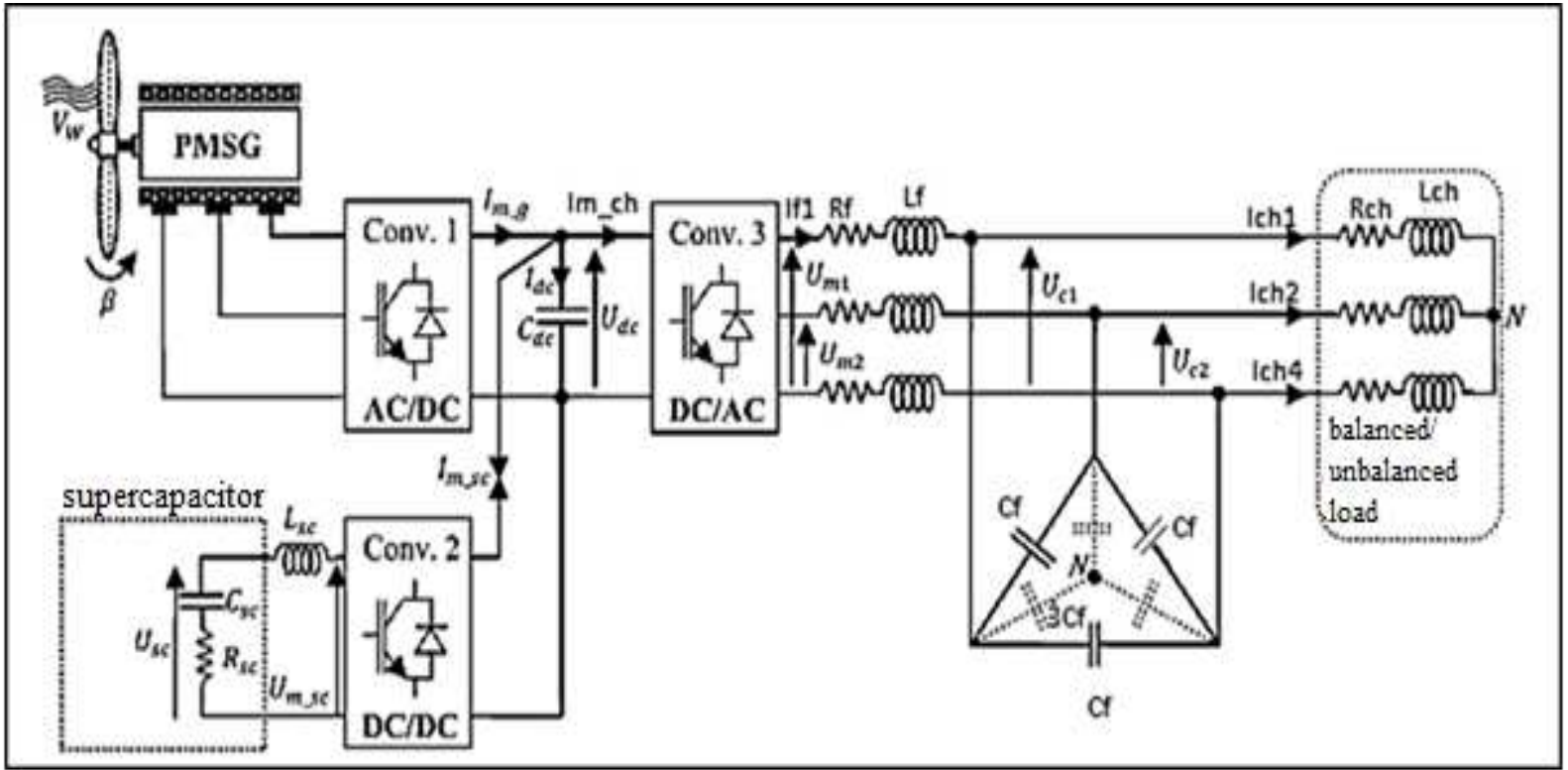

Fig.1. Energy conversion system adapted from [9]

\subsection{Modeling the wind turbine}

The wind turbine converts the kinetic energy of the wind into mechanical energy. To model the behavior of that component, it is necessary to determine the mechanical torque produced from the extracted power of the wind.

The mechanical torque of the turbine based on the extracted power is given by [9]:

$$
C_{m}=P_{v} / \Omega
$$

Where:

$$
P_{v}=0.5 \times \rho \times \pi \times R^{2} \times v_{w}^{3} \times C_{p}(\lambda, \beta)
$$

$R$ is the radius of the blade (in $m$ ), $\rho$ air density (in $k g . \mathrm{m}^{-3}$ ) and $v_{w}$ the wind speed (in $m . \mathrm{s}^{-1}$ ).

The power coefficient $C_{p}(\lambda, \beta)$ can be expressed as a function of the specific speed $\lambda$ and 
the pitch angle $\beta$ as [9]:

$C_{p}(\lambda, \beta)=0.53\left[\frac{151}{\lambda_{i}}-0.58 \beta-0.002 \beta^{2.14}-13.2\right] \exp \left(-\frac{18.4}{\lambda_{i}}\right)$

Where:

$$
\lambda_{i}=\frac{1}{\frac{1}{\lambda-0.02 \beta}-\frac{0.0003}{\beta^{2}+1}}
$$

We also have [9]:

$$
\lambda=\frac{R \Omega}{v_{w}}
$$

Figure 2 shows how the power coefficient varies with the specific speed for various blade angles. It could be seen that for $\beta=0$, the optimum specific speed is $\lambda_{\text {opt }}=8$ and the maximum power coefficient $\mathrm{C}_{\mathrm{pmax}}=0.4185$.

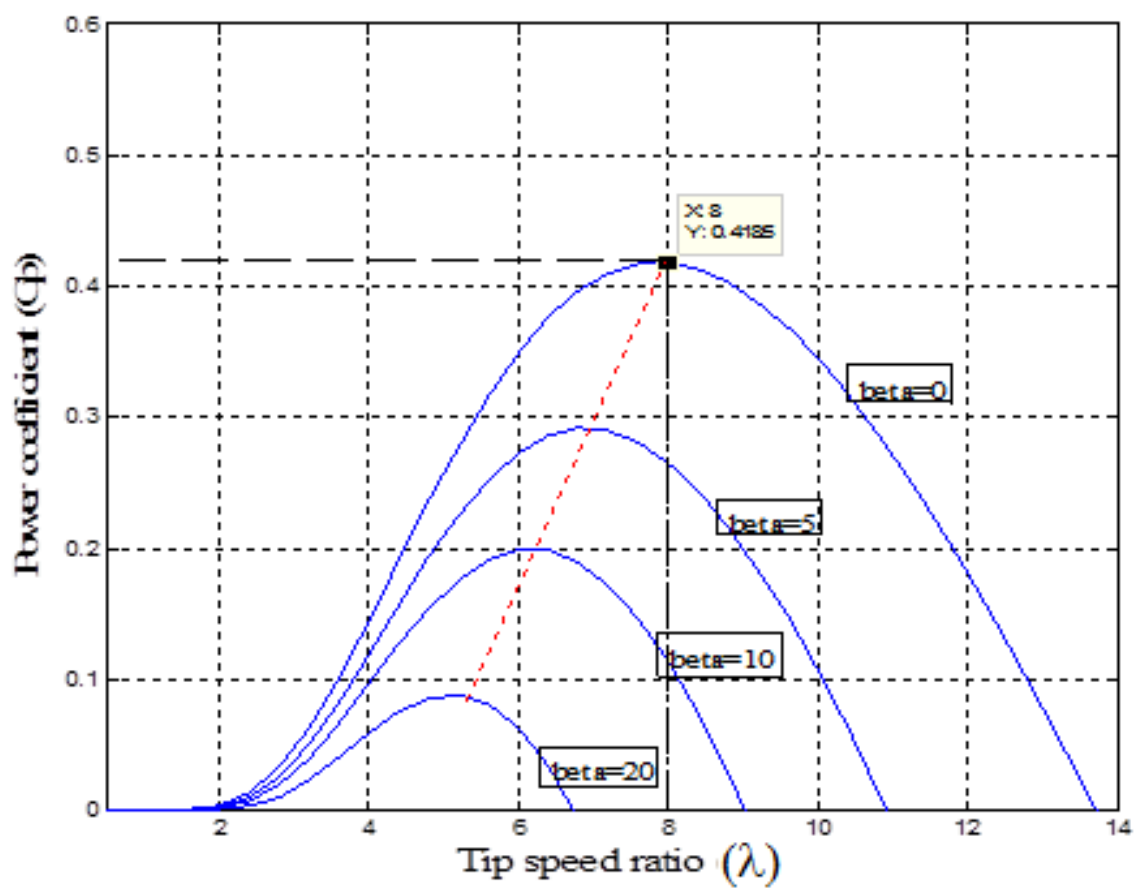

Fig.2. Characteristics of the wind turbine

The rotational speed $\Omega$ is obtained from the fundamental equation of dynamics [10]:

$$
J \frac{d \Omega}{d t}=C_{m}-C_{e m}-f \Omega
$$

Where $J$ is the moment of inertia of the shaft (in $k g . \mathrm{m}^{2}$ ); $f$ the friction coefficient of the shaft; 
and $C_{e m}$ the electromagnetic torque.

The turbine is controlled in order to extract a maximum power from the wind. The maximum power extracted using MPPT methods is given by the expression [9]:

$P_{M P P T}=K \Omega^{3}$

With:

$$
K=0.5 \frac{\rho \pi R^{5} C_{p \max }}{\lambda_{o p t}^{3}} K \Omega^{3}
$$

The control of the setting angle $\beta$ enables to limit the extracted power so that to protect the turbine from high wind speed.

From the above expressions the following block diagram can be obtained (figure 3):

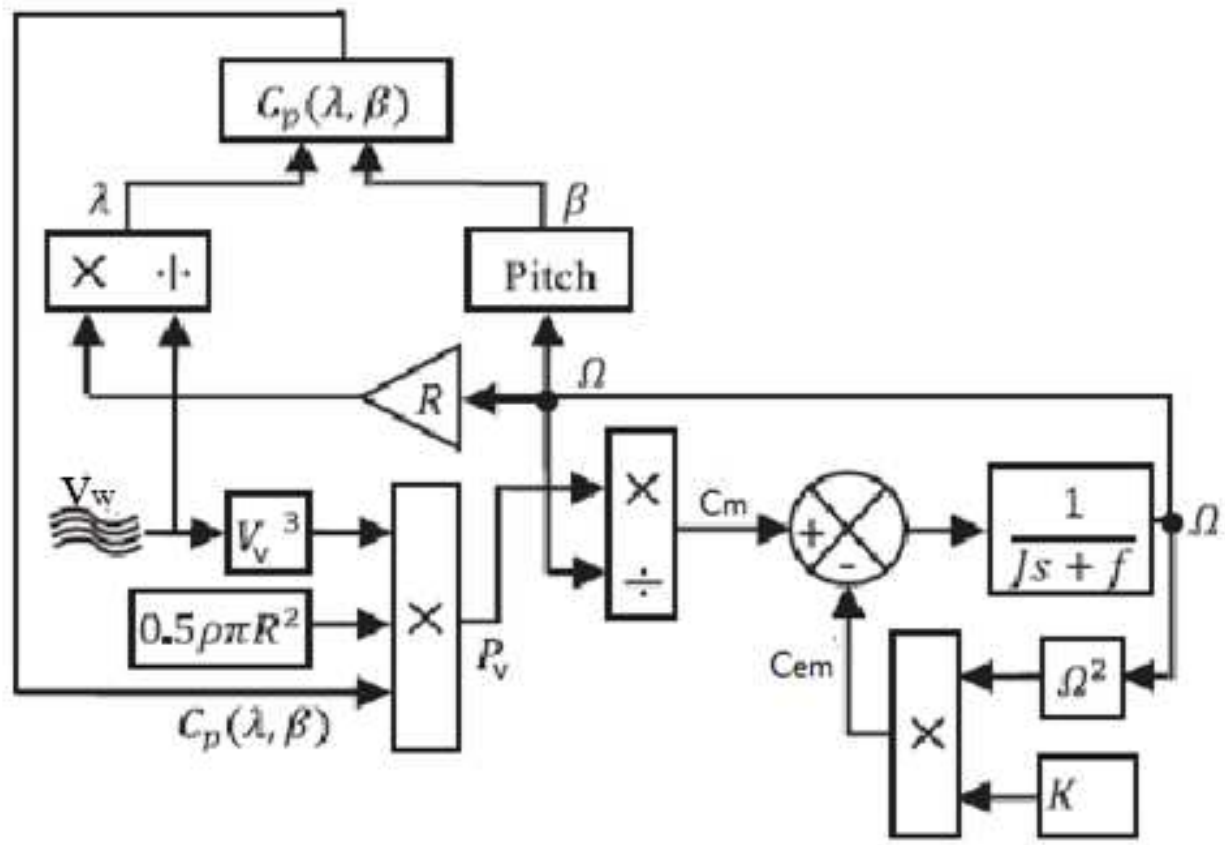

Fig.3. Block diagram of the model of the turbine adapted from [9]

\subsection{Modeling and control of the PMSG}

The permanent magnet synchronous machine is the part of the energy conversion system, which converts the mechanical energy of the turbine into electrical energy. In this work we assume a radial flow and smooth pole $\left(L_{q}=L_{d}=L_{s}\right)$. Conventionally, the model in the reference of Park gives the following equations [10]:

$V_{s d}=R_{s} I_{s d}+L_{s} \frac{d I_{s d}}{d t}-p \Omega L_{s} I_{s q}$ 
$V_{s q}=R_{s} I_{s q}+L_{s} \frac{d I_{s q}}{d t}+p \Omega L_{s} I_{s d}+p \Omega \Phi_{m}$

$\omega=p \Omega$

The electromechanical torque developed by synchronous machines at sinusoidal electromotive force may be given by the following equation [10]:

$C_{e m}=\frac{3}{2} p \Phi_{m} I_{s q}$

To control the electric power generation, we can just manage the electromagnetic torque $C_{e m}$ by controlling the stator currents through proportional integral controllers (PI) as shown in figure 4 .

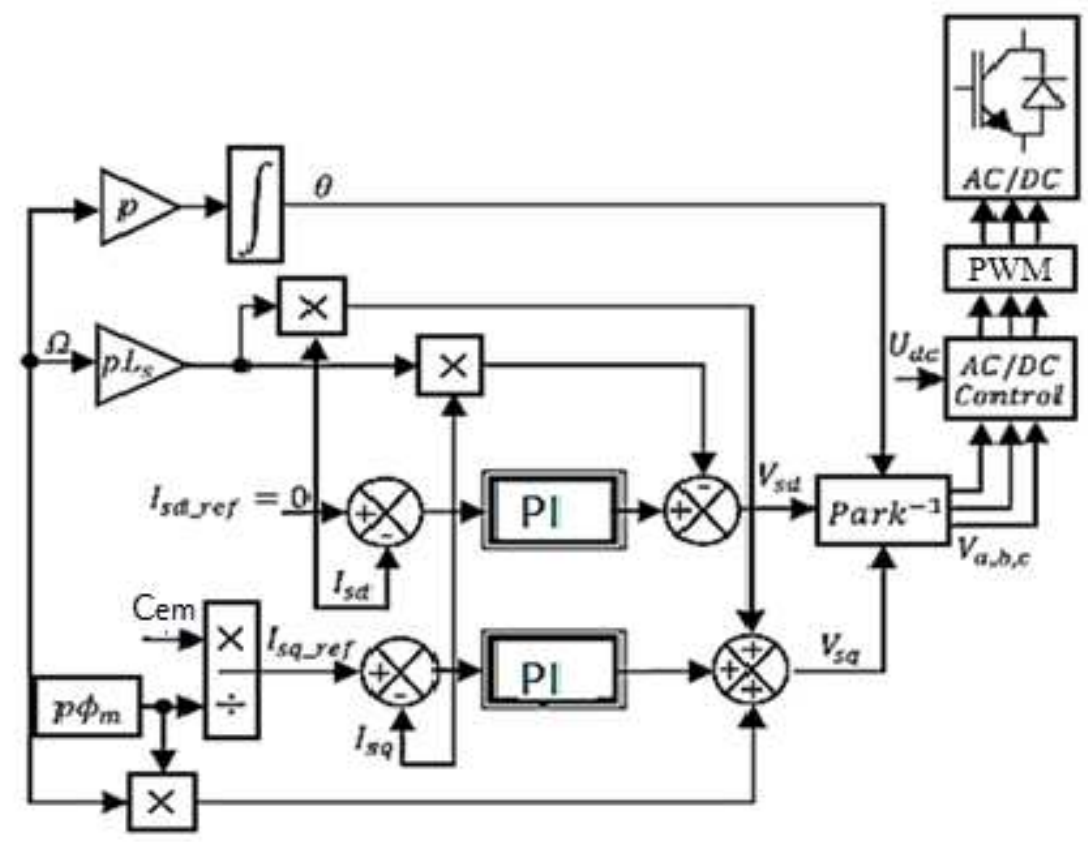

Fig.4. Block diagram of the control of the synchronous machine

\subsection{Model of the storage system}

The storage system is made of super-capacitors. The electrical model of the supercapacitor consists to a capacitor $C_{s c}$ which represents the capacity of the supercapacitor, and a resistor $R_{s c}$ representing the resistance of charge/discharge, and finally a resistor $r_{s c}$ representing the internal leakage (figure 5). 


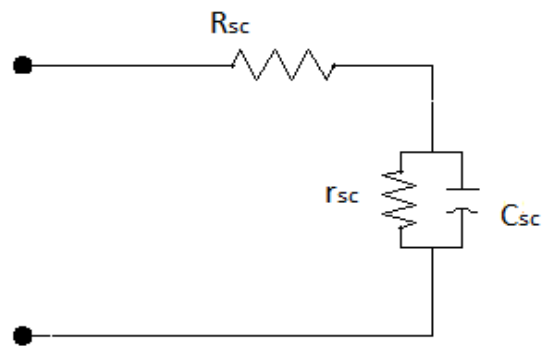

Fig.5. Electrical model of the supercapacitor [9]

Neglecting the resistance that models the internal leakage, the expressions of the equation of the charge (eqn. 13) and discharge (eqn. 14) of the supercapacitor are given by:

$$
\begin{aligned}
& V_{s c}=U_{s c_{-} \text {charge }}\left(1-\exp \left(-\frac{t}{R_{s c} C_{s c}}\right)\right) \\
& U_{s c_{-} \text {discharge }}=V_{s c} \exp \left(-\frac{t}{R_{s c} C_{s c}}\right)
\end{aligned}
$$

Current control (figure 6) super capacitor connected to the DC bus via a bidirectional converter is necessary to control the charge/discharge voltages. We therefore have the following equation:

$$
U_{m_{-} s c}=U_{s c}-P I\left(I_{s c r e f}-I_{s c}\right)
$$

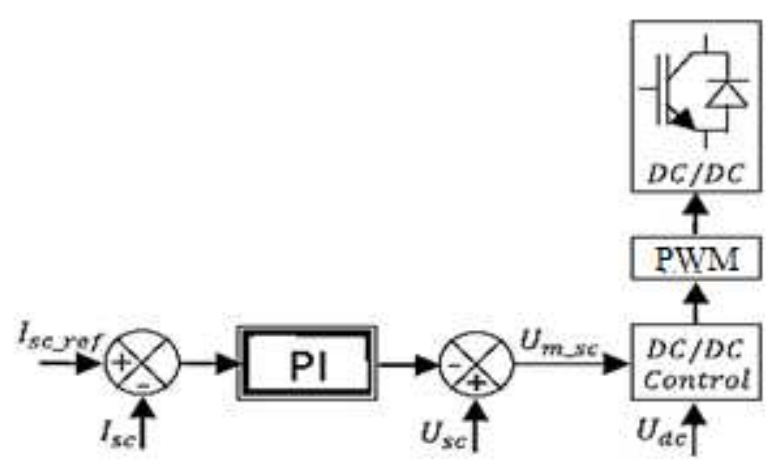

Fig.6. Controlling the current storage system

\subsection{Modeling of the DC bus}

The DC bus is the transit point for power to ensure the stability of the network. It behaves like a source of constant DC voltage. The following equation could be obtained from figure 7:

$$
I_{d c}=C_{d c} \frac{d U_{d c}}{d t}=I_{m_{-} g}+I_{m_{-} \mathrm{sc}}-I_{c h}
$$


Where $C_{d c}$ is the capacity of the DC bus (in $F$ ); $I_{d c}$ the DC bus current (in $A$ ); $I_{m \_s c}$ the output current of the storage system (in $A$ ); $I_{m_{-g}}$ the current generated by wind (in $A$ ); and $I_{c h}$ the current load of the network (in $A$ ).

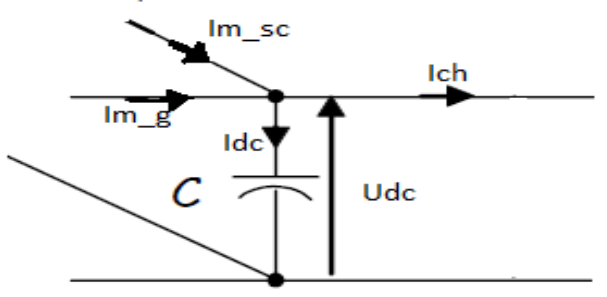

Fig.7. Electrical model of the DC bus

\subsection{Modeling of the filter}

The DC bus voltage is converted to AC voltage. This conversion is accompanied by harmonics due to the nonlinear nature of the static converter. A filter is generally interposed against these harmonics and improves the power quality in the network. In this work a LC filter is used. From figure 8 one can write:

$$
\begin{aligned}
& \frac{d}{d t}\left[\begin{array}{l}
I_{f 1} \\
I_{f 2} \\
I_{f 3}
\end{array}\right]=\frac{1}{3 L_{f}}\left(\begin{array}{cc}
2 & -1 \\
-1 & 2 \\
-1 & -1
\end{array}\right)\left[\begin{array}{l}
U_{m 1}-U_{c 1} \\
U_{m 2}-U_{c 2}
\end{array}\right]-\frac{R_{f}}{L_{f}}\left(\begin{array}{lll}
1 & 0 & 0 \\
0 & 1 & 0 \\
0 & 0 & 1
\end{array}\right)\left[\begin{array}{c}
I_{f 1} \\
I_{f 2} \\
I_{f 3}
\end{array}\right] \\
& \frac{d}{d t}\left[\begin{array}{l}
U_{c 1} \\
U_{c 2}
\end{array}\right]=\frac{1}{3 C_{f}}\left(\begin{array}{ll}
2 & 1 \\
1 & 2
\end{array}\right)\left[\begin{array}{l}
I_{f 1}-I_{c h 1} \\
I_{f 2}-I_{c h 2}
\end{array}\right]
\end{aligned}
$$

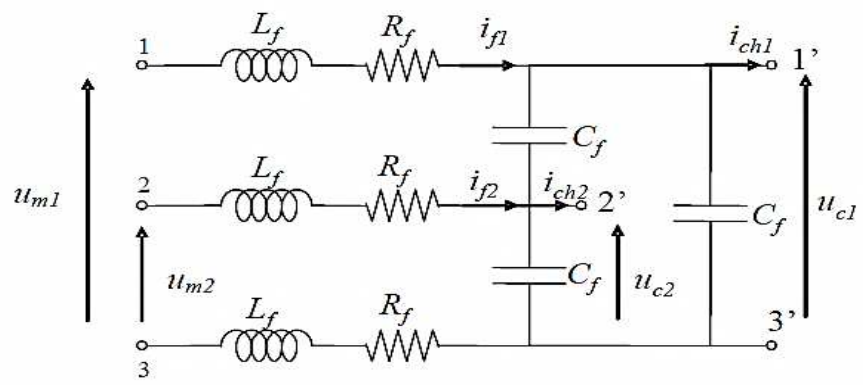

Fig.8. LC filter [8]

The transmittance $T(s)$ can be determined by using the following equivalent phase diagram: 


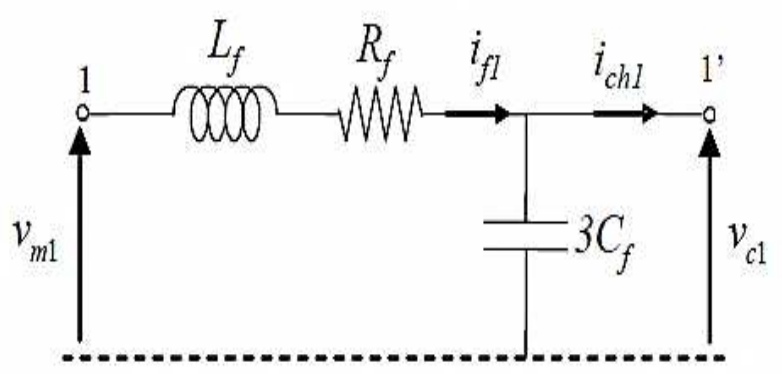

Fig.9. Schematic equivalent phase filter [8]

$T_{s}=\frac{v_{c 1}}{v_{m 1}}=\frac{U_{c 1 \text { or } 2}}{U_{m 1 \text { or } 2}}=\frac{1}{1+3 R_{f} C_{f} s+3 L_{f} C_{f} s^{2}}$

The transfer function of the second order filter is given by:

$$
T(s)=\frac{1}{1+\frac{2 z}{\omega_{n}} s+\frac{s^{2}}{\omega_{n}^{2}}}
$$

Where $z$ is the damping coefficient and $\omega_{n}$ the natural pulsation (in $\mathrm{rad} . \mathrm{s}^{-1}$ ) characterizing the filter:

$$
\begin{aligned}
& z=\frac{3 R_{f} C_{f}}{2} \omega_{n} \\
& \omega_{n}=\frac{1}{\sqrt{3 L_{f} C_{f}}}=2 \pi f_{n}
\end{aligned}
$$

Figure 10 presents an example of location of a Bode transmittance of the second-order for a natural frequency $f_{n}=50 \mathrm{~Hz}$ and values of $\mathrm{z}$ equal to $0.3,0.4,0.5,0.7,0.8$.

The filter elements are sized to the cutoff frequency $f_{c}$ defined as the frequency for which the signal amplitude is attenuated by $-3 \mathrm{~dB}$. 


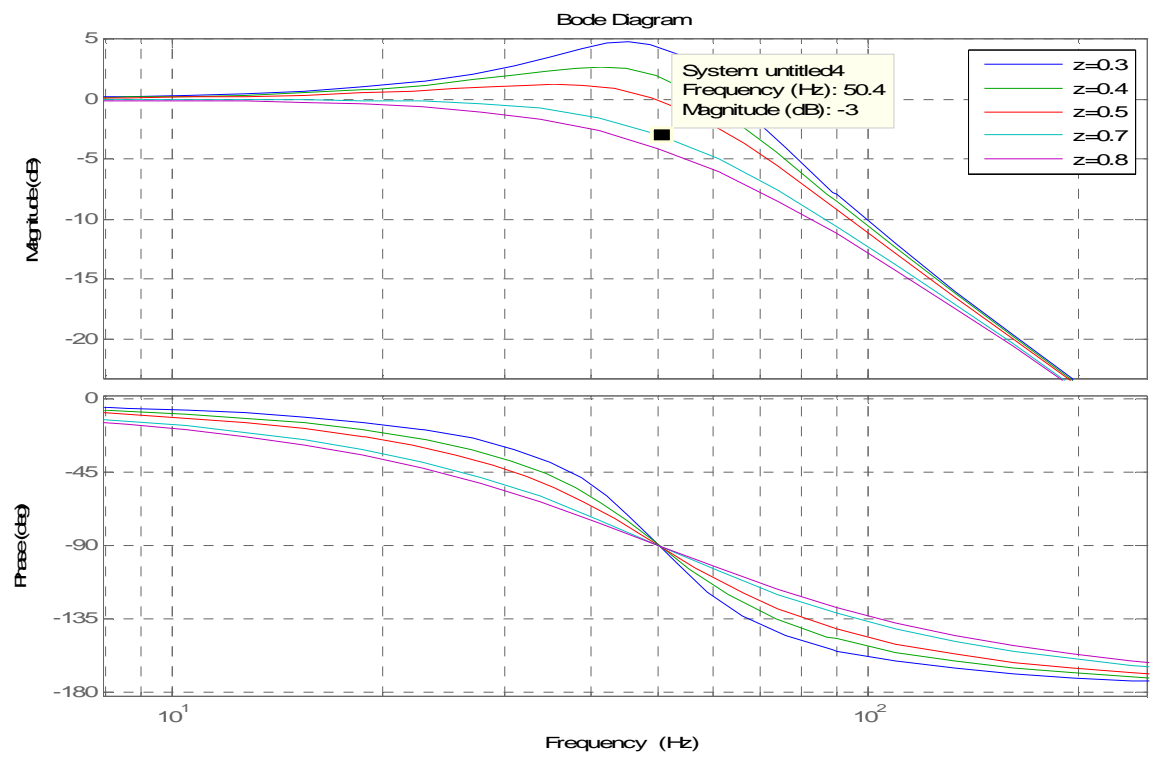

Fig.10. Bode plot of the transmittance of the second order

\subsection{Model of the load}

The energy conversion system shown in figure 1 supply a three-phase balanced or not load (resistive + inductive). To model this support, active power $P_{c h i}$ and reactive $Q_{c h i}$ are considered under a voltage $V_{c i}$ and a frequency $\omega=100 \mathrm{rad}_{\mathrm{s}} \mathrm{s}^{-1}$. The following relations are obtained:

$$
\begin{aligned}
R_{c h i} & =\frac{V_{c i}^{2} P_{c h i}}{P_{c h i}^{2}+Q_{c h i}^{2}} \\
L_{c h i} & =\frac{V_{c i}^{2} Q_{c h i}}{\left(P_{c h i}^{2}+Q_{c h i}^{2}\right) \omega}
\end{aligned}
$$

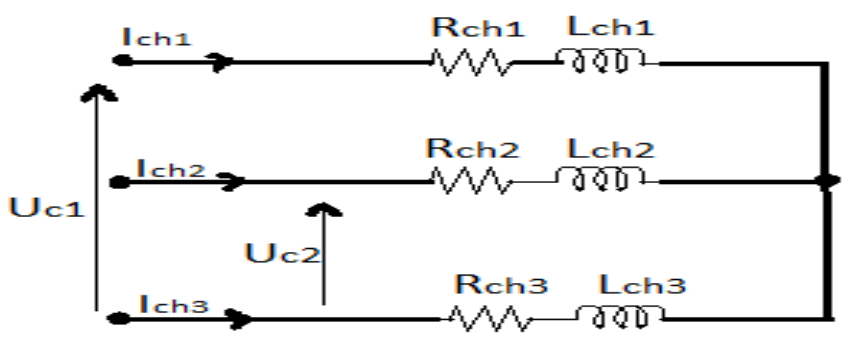

Fig.11. Electric Load Model RL

From figure 11, the expressions of the load currents could be written in matrix form. Neglecting the mutual inductances, one can write: 
$\frac{d}{d t}\left[\begin{array}{l}I_{c h 1} \\ I_{c h 2} \\ I_{c h 3}\end{array}\right]=\frac{1}{L}\left\{[M 1]\left[\begin{array}{c}I_{c h 1} \\ I_{c h 2} \\ I_{c h 3}\end{array}\right]+[M 2]\left[\begin{array}{c}U_{c 1} \\ U_{c 2}\end{array}\right]\right\}$

with

$[M 1]=\left[\begin{array}{ccc}-X_{11} & 0 & X_{13} \\ X_{21} & -X_{22} & 0 \\ X_{31} & 0 & -X_{33}\end{array}\right]$ and $[M 2]=\left[\begin{array}{cc}L_{c h 2}+L_{c h 3} & -L_{c h 3} \\ -L_{c h 3} & L_{c h 1}+L_{c h 3} \\ -L_{c h 2} & -L_{c h 1}\end{array}\right]$

$L=L_{c h 1} L_{c h 2}+L_{c h 1} L_{c h 3}+L_{c h 2} L_{c h 3}$

The parameters of the matrix [M1] are given in Table 1.

Table 1. Parameters of the matrix [M1]

\begin{tabular}{ll}
\hline Parameter & Expression \\
\hline$X_{11}$ & $R_{c h 1} L_{c h 2}+R_{c h 1} L_{c h 3}+R_{c h 2} L_{c h 3}$ \\
$X_{22}$ & $R_{c h 2} L_{c h 3}+R_{c h 2} L_{c h 1}+R_{c h 3} L_{c h 1}$ \\
$X_{33}$ & $R_{c h 3} L_{c h 2}+R_{c h 2} L_{c h 1}+R_{c h 3} L_{c h 1}$ \\
$X_{13}$ & $R_{c h 3} L_{c h 2}-R_{c h 2} L_{c h 3}$ \\
$X_{21}$ & $R_{c h 1} L_{c h 3}-R_{c h 3} L_{c h 1}$ \\
$X_{31}$ & $R_{c h 1} L_{c h 2}-R_{c h 2} L_{c h 1}$ \\
\hline
\end{tabular}

\subsection{Regulation of the DC bus voltage}

Regulating the DC bus is done through the storage element that maintains the balance between production and consumption. Multiplying equation (16) by $U_{d c}$ the balance of instantaneous power is obtained as follows:

$$
\begin{aligned}
& C_{d c} \frac{d U_{d c}}{d t} U_{d c}=\Delta P=P_{g}+P_{s c}-P_{c h} \\
& C_{d c} \frac{d U_{d c}}{d t}=\frac{\Delta P}{U_{d c}}=I_{d c}
\end{aligned}
$$

Where:

$P_{s c}$ is the Power storage system (in W); $P_{g}$ the power generated by the wind energy (in W); 
$P_{c h}$ the Power load connected to the network (in W).

From equations (26) and (27) one can establish the COG (Causal Ordering Graph) of DC bus that will allow determining the order (fig. 12) [8] whose parameters are presented in table 2:

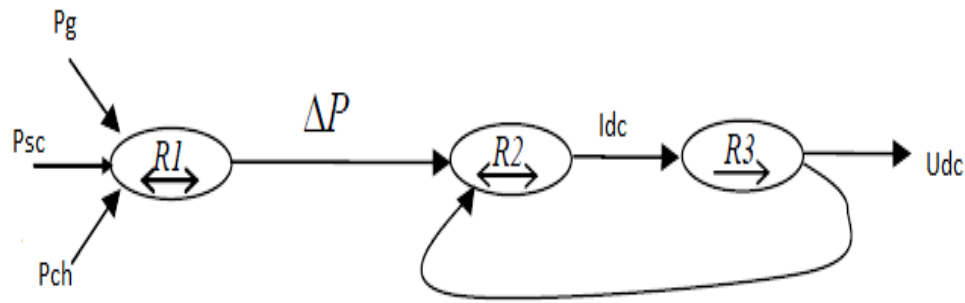

Fig.12. COG of DC bus

Table 2. COG Equations of DC bus

\begin{tabular}{ll}
\hline Parameter & Expression \\
R1 & $\Delta P=P_{g}+P_{s c}-P_{c h}$ \\
$\mathrm{R} 2$ & $I_{d c}=\frac{\Delta P}{U_{d c}}$ \\
$\mathrm{R} 3$ & $C_{d c} \frac{d U_{d c}}{d t}=I_{d c}$ \\
\hline
\end{tabular}

The inversion of the COG in Figure 12 gives the diagram presented in fig. 13 whose parameters are presented in table $3[8]$ :

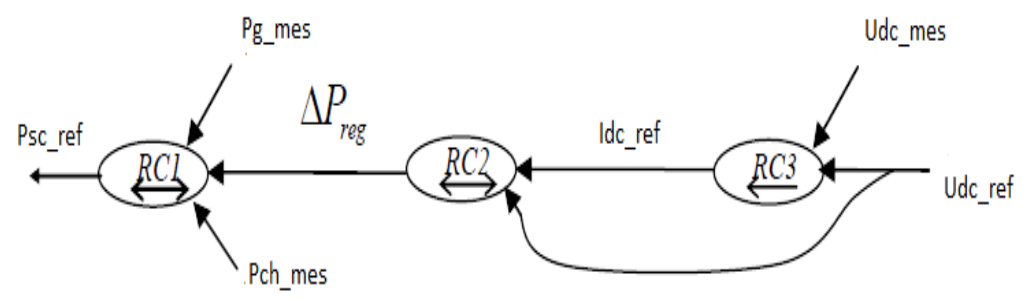

Fig.13. COG of the DC bus control 
Table 3. COG equations of the DC bus control

\begin{tabular}{ll}
\hline Parameter & Expression \\
\hline $\mathrm{RC} 1$ & $P_{s c_{-} r e f}=\Delta P_{\text {reg }}-P_{g_{-} \text {mes }}+P_{c c_{-} \text {mes }}$ \\
$\mathrm{RC} 2$ & $\Delta P_{\text {reg }}=U_{d c_{-} r e f} \cdot I_{d c_{-} r e f}$ \\
$\mathrm{RC} 3$ & $I_{d c_{-} r e f}=C(s)\left(U_{d c_{-} r e f}-U_{d c_{-} \text {mes }}\right)$ \\
\hline
\end{tabular}

$C(s)$ is a PI controller.

Figure 14 shows the block diagram of the control strategy of the DC bus.

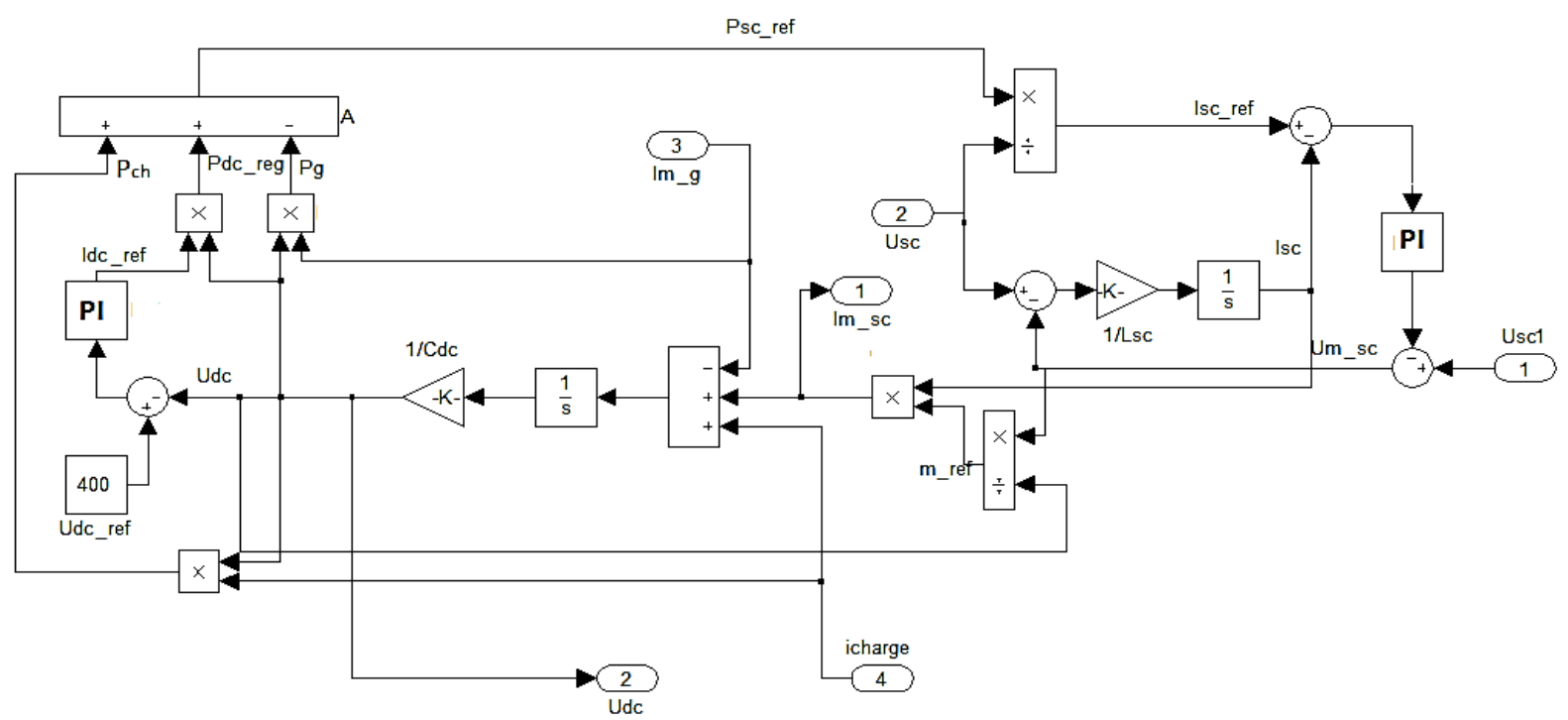

Fig.14. Block diagram of the control strategy of the DC bus

\subsection{Regulation of the output voltages of the filter}

Using the COG equation of the filter (figure 15) and the reverse (figure 16), one gets control of the network interface with the parameters presented in tables 4 and 5 .

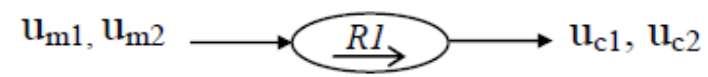

Fig.15. COG of filter 
Table 4. COG equation filter

\section{Parameter Expression}

$\mathrm{R} 1 \quad U_{c 1 \text { or } 2}=\frac{1}{1+3 R_{f} C_{f} s+3 L_{f} C_{f} s^{2}} U_{m 1 \text { or } 2}$

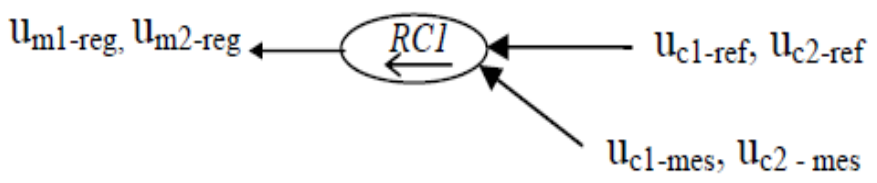

Fig.16. COG of filter control

Table 5. COG equation of filter control

\begin{tabular}{ll} 
Parameter & Expression \\
\hline $\mathrm{RC} 1$ & $U_{m 1_{-} r e f}=C_{r}(s)\left(U_{c 1_{-} r e f}-U_{c 1 \_\mathrm{mes}}\right)$ \\
& $U_{m 2_{2} r e f}=C_{r}(s)\left(U_{c 2_{-} r e f}-U_{c 2_{-} \mathrm{mes}}\right)$ \\
\hline
\end{tabular}

Since we have AC voltage, we use proportional resonant correction. This type of correction is well suited to control sinus voltages $[11,12]$. A wide synthesis of comparator is explained by Zmood et al. [13].

The correction is of the form:

$C_{r}(s)=K_{p}+\frac{K_{i} s}{s^{2}+\omega_{0}^{2}}$

Where $\omega_{0}$ is the angular frequency of the controlled variable (in $\mathrm{rad} / \mathrm{s}$ ); $K_{p}$ and $K_{i}$ are the parameters of the controller to be determined.

The method of determining the parameters of the controller consists to locate the poles of the transfer function of the closed loop system. The choice of the poles is such that their real part is negative.

The transfer function in open loop $(O L T F)$ of the corrected system is:

$$
\operatorname{OLTF}(s)=\left(K_{p}+\frac{K_{i} s}{s^{2}+\omega_{0}^{2}}\right) \cdot\left(\frac{1}{1+3 R_{f} C_{f} s+3 L_{f} C_{f} s^{2}}\right)
$$


Table 6. Filter settings

\begin{tabular}{ll}
\hline Parameter & Expression \\
\hline$a_{2}$ & $3 L_{f} C_{f}$ \\
$a_{1}$ & $3 R_{f} C_{f}$ \\
$a_{0}$ & 1 \\
\hline
\end{tabular}

The transfer function in a closed loop $(C L T F)$ :

$\operatorname{CLTF}(s)=\frac{K_{p} s^{2}+K_{i} s+K_{p} \omega_{0}^{2}}{a_{2} s^{4}+a_{1} s^{3}+\left(K_{p}+a_{0}+a_{2} \omega_{0}^{2}\right) s^{2}+\left(a_{1} \omega_{0}^{2}+K_{i}\right) s+\left(K_{p}+a_{0}\right) \omega_{0}^{2}}$

The general characteristics of the polynomial of degree 4 is of the following form:

$\Delta \mathrm{P}(s)=\left(s+s_{1}\right)^{2}\left(s+s_{2}\right)^{2}$

Table 7. Choice of poles

\begin{tabular}{ll}
\hline Pole & expression \\
\hline$s_{1}$ & $\rho(-1-j)$ \\
$s_{2}$ & $\rho(-1+j)$
\end{tabular}

$\rho$ is a positive real number, we choose properly taking into account the criteria of stability and speed of correction.

Table 8. Parameters of correction

\begin{tabular}{ll}
\hline Parameter & Expression \\
\hline$K_{p}$ & $4 \rho^{2}-a_{0}-a_{2} \omega_{0}^{2}$ \\
$K_{i}$ & $-8 \rho^{3}-a_{1} \omega_{0}^{2}$ \\
\hline
\end{tabular}

The voltages $U_{c 1}$ and $U_{c 2}$ are compared with their respective reference voltage $U_{c 1 r e f}$ and $U_{c 2 r e f}$. Errors are adjusted by the proportional resonant markers established. At the end of the correction we have regulated voltages $U_{m 1 r e g}$ and $U_{m 2 r e g}$ that allow developing the control signal MLI of DC / AC converter. 


$$
\begin{aligned}
& U_{\text {c1ref }}=\sqrt{2} \cdot U_{\text {eff }} \sin \left(\omega t-\frac{\pi}{6}\right) \\
& U_{c 2 \text { ref }}=\sqrt{2} \cdot U_{e f f} \sin \left(\omega t-\frac{\pi}{2}\right)
\end{aligned}
$$

Figure 17 shows the block diagram of the control strategy of voltages.

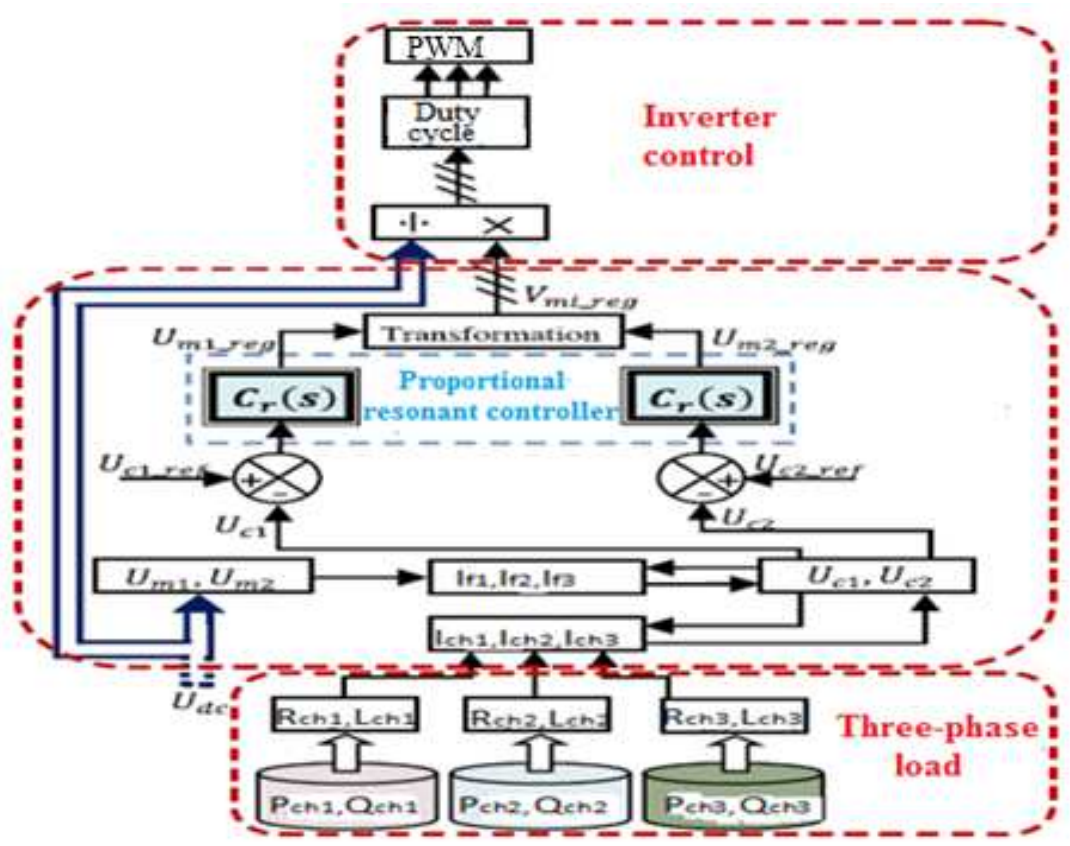

Fig.17. Block diagram of the control strategy

\section{RESULTS AND DISCUSSION}

The implementation of these models in Matlab-Simulink, give results presented in this section.

The characteristics of the energy conversion system are presented in table 9 .

Table 9. Elements of the energy conversion system

\begin{tabular}{|l|l|}
\hline Wind turbine & $\begin{array}{l}\text { Blade radius } \mathrm{R}=1.7 \mathrm{~m} \\
\text { Number of blades } \mathrm{NB}=3\end{array}$ \\
\hline PMSG & $\begin{array}{l}\text { Number of pair of poles } \mathrm{p}=4 ; \\
\text { Rs=0.82 } \Omega ; \\
\text { Inductance } \mathrm{Ls}=15 \mathrm{mH} ; \\
\text { Rotor flux } \Phi \mathrm{m}=0.5 \mathrm{~Wb} \\
\text { Inertia of the shaft } \mathrm{J}=99.10^{-4} \mathrm{Kgm}^{2} ; \\
\text { Friction coefficient } \mathrm{f}=10^{-3} \mathrm{~N} \cdot \mathrm{m} \cdot \mathrm{s} \cdot \mathrm{rad}^{-1}\end{array}$ \\
\hline Supercapacitor & $\begin{array}{l}\text { Capacitance } \mathrm{Csc}=94 \mathrm{~F}+20-0 \% ; \\
\text { Resistor of charge } / \text { discharge } \mathrm{Rsc}=12.5 \mathrm{~m} \Omega ; \\
\text { Voltage Vsc }=75 \mathrm{~V} \\
\text { maximum continuous current Imax }=50 \mathrm{~A}\end{array}$ \\
\hline DC bus & $\begin{array}{l}\text { Capacitance Cdc }=2200 \mu \mathrm{F} ; \\
\text { Maximum voltage } \mathrm{Udc}=800 \mathrm{~V}\end{array}$ \\
\hline
\end{tabular}


The wind speed profile studied, adapted from [9] is shown in Figure 18.The value of the wind speed is between $5.9 \mathrm{~m} / \mathrm{s}$ and $13 \mathrm{~m} / \mathrm{s}$.

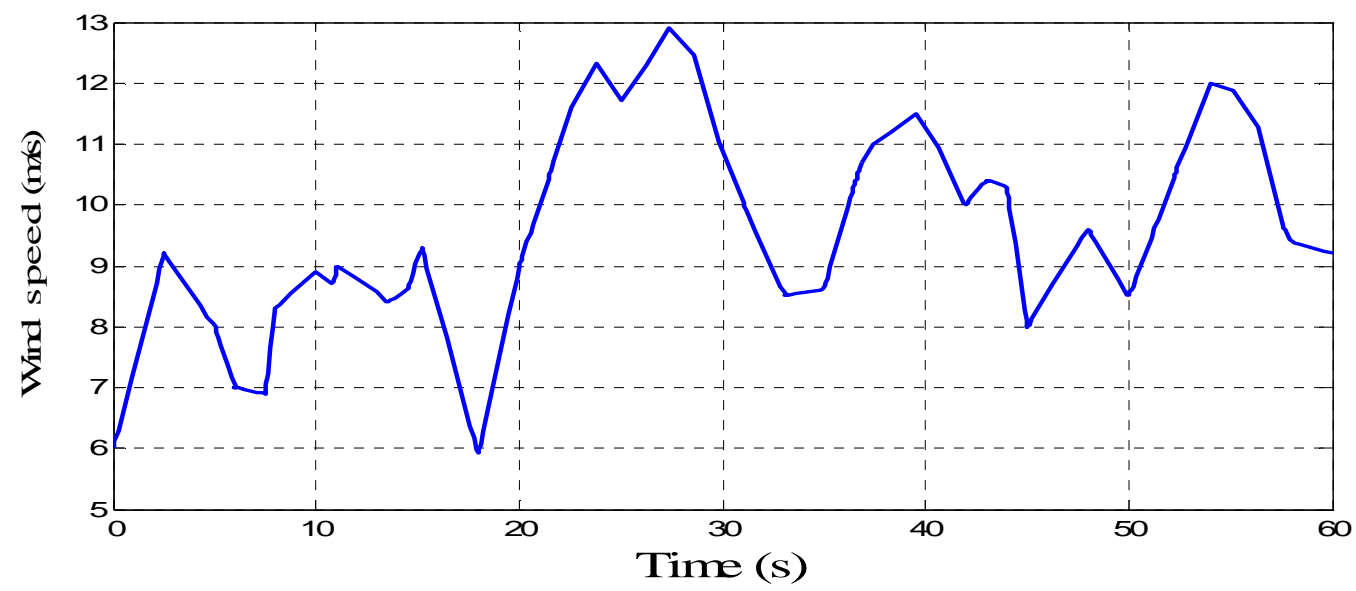

Fig.18. Wind Profile

These speeds are applied to our model whose turbine design speed is $10.5 \mathrm{~m} / \mathrm{s}$. A MPPT method is used to extract maximum power from the wind and control the angle of attack so that to protect the turbine from high speed.

Figure 19 shows the variation of the pitch angle with time. It may be noted that the value of the setting angle increases in wind speeds above the rated speed, while the power coefficient decreases (fig. 20) thereby limiting the rotational speed (figure 21) and the wind power extracted (fig. 22) to protect the wind turbine to heavy wind speeds and to extract maximum energy. When the pitch angle is zero, the power coefficient is maximum.

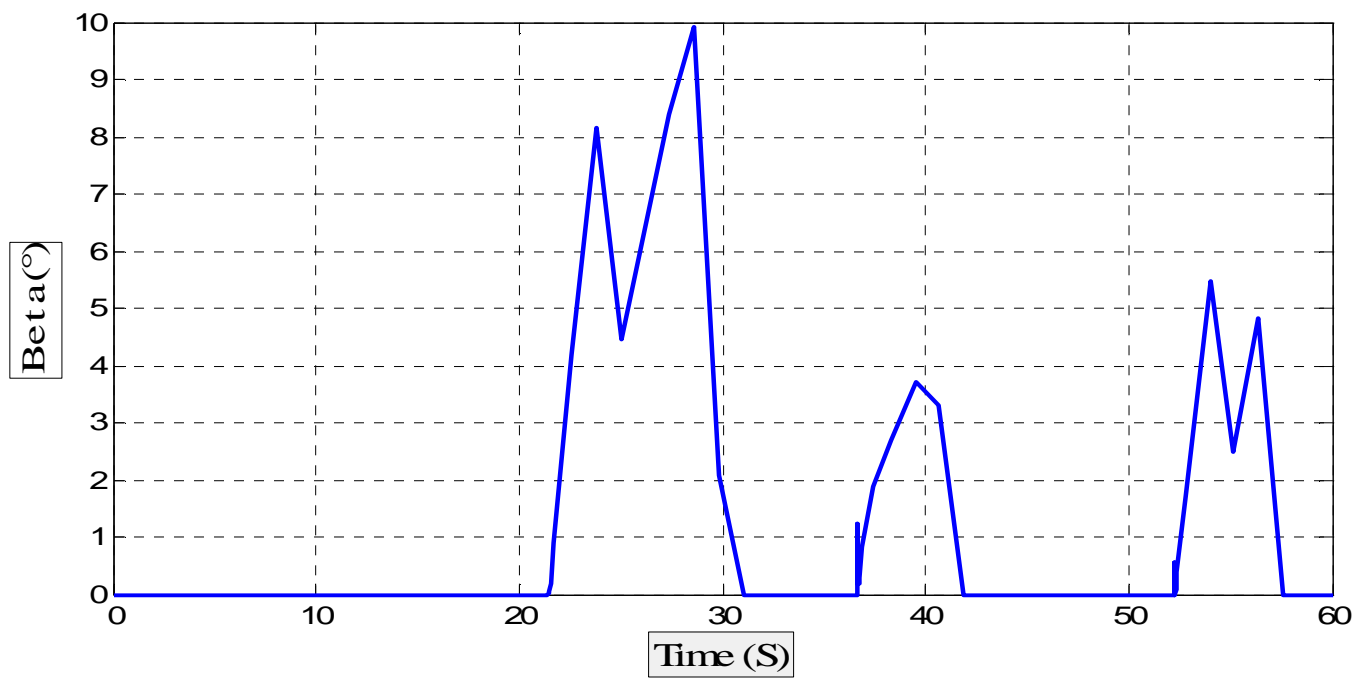

Fig.19. Evolution of the pitch angle 


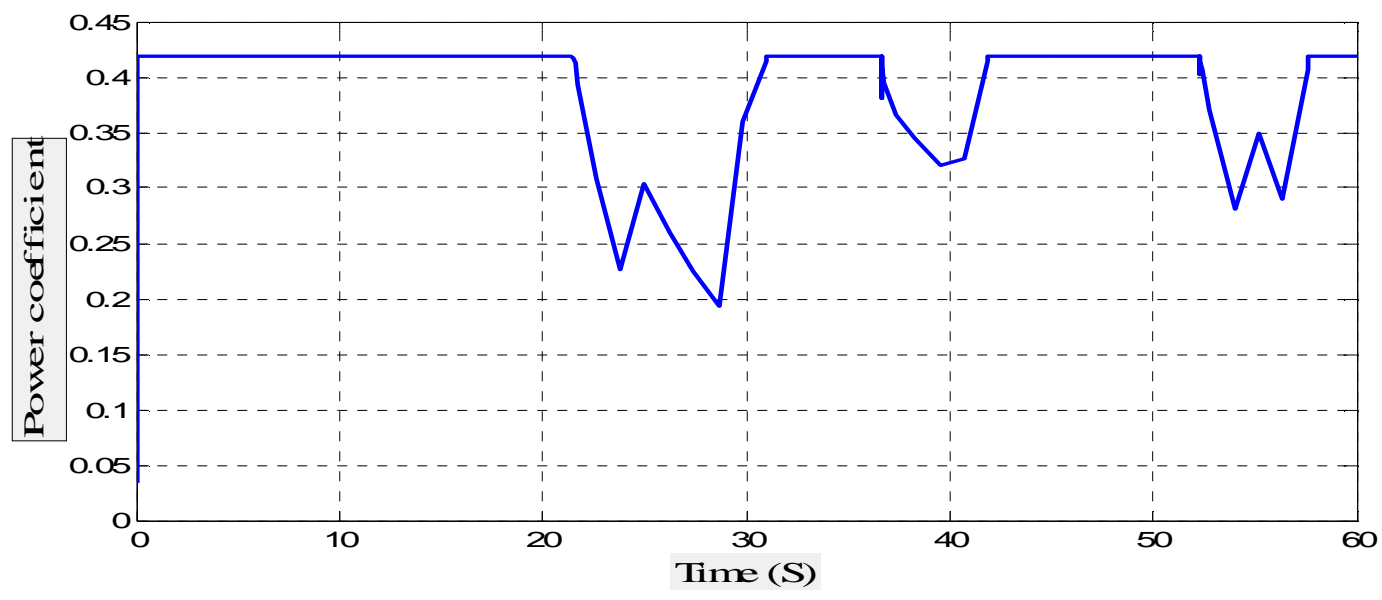

Fig.20. Evolution of the power coefficient

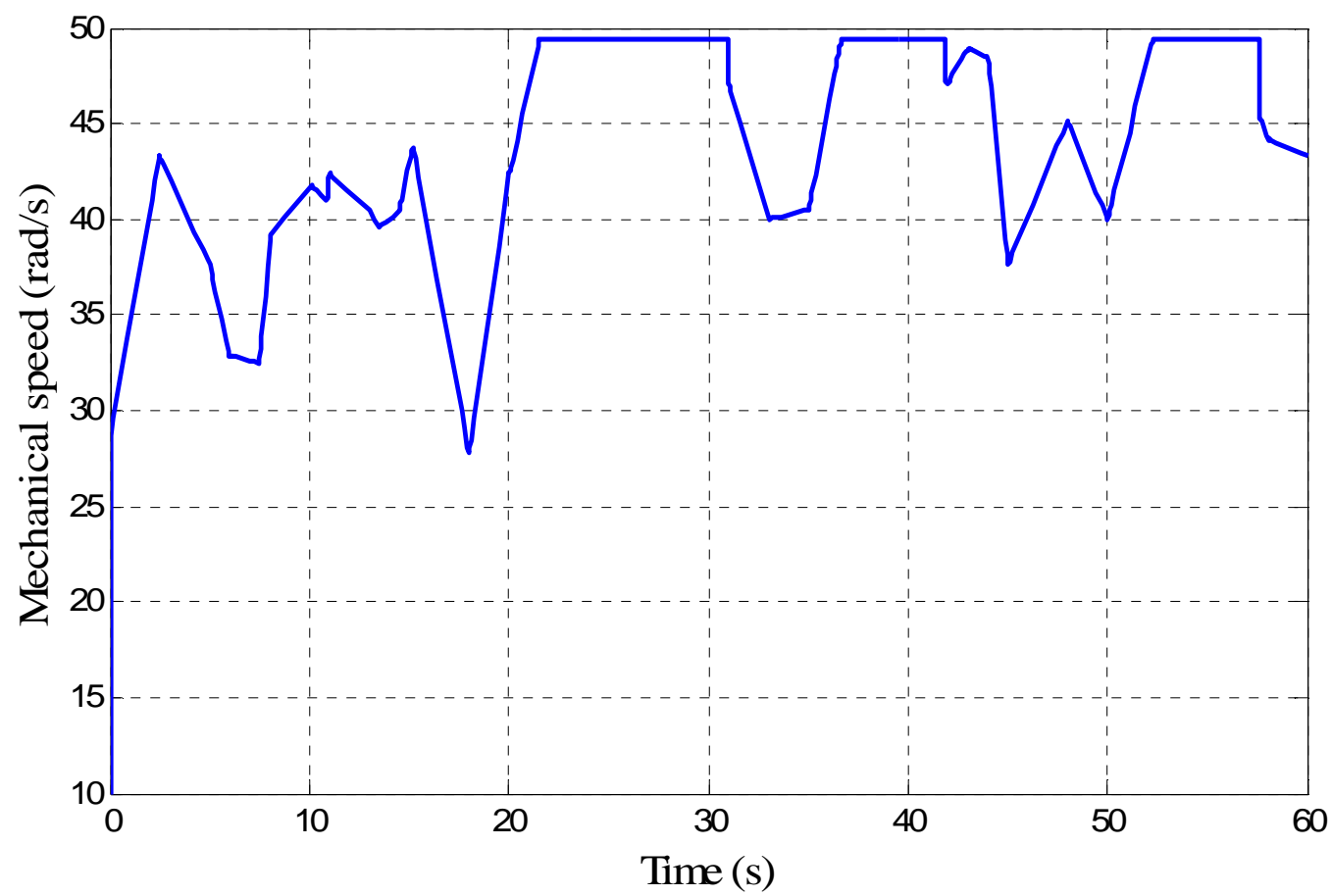

Fig.21. Rotational speed of the turbine shaft 


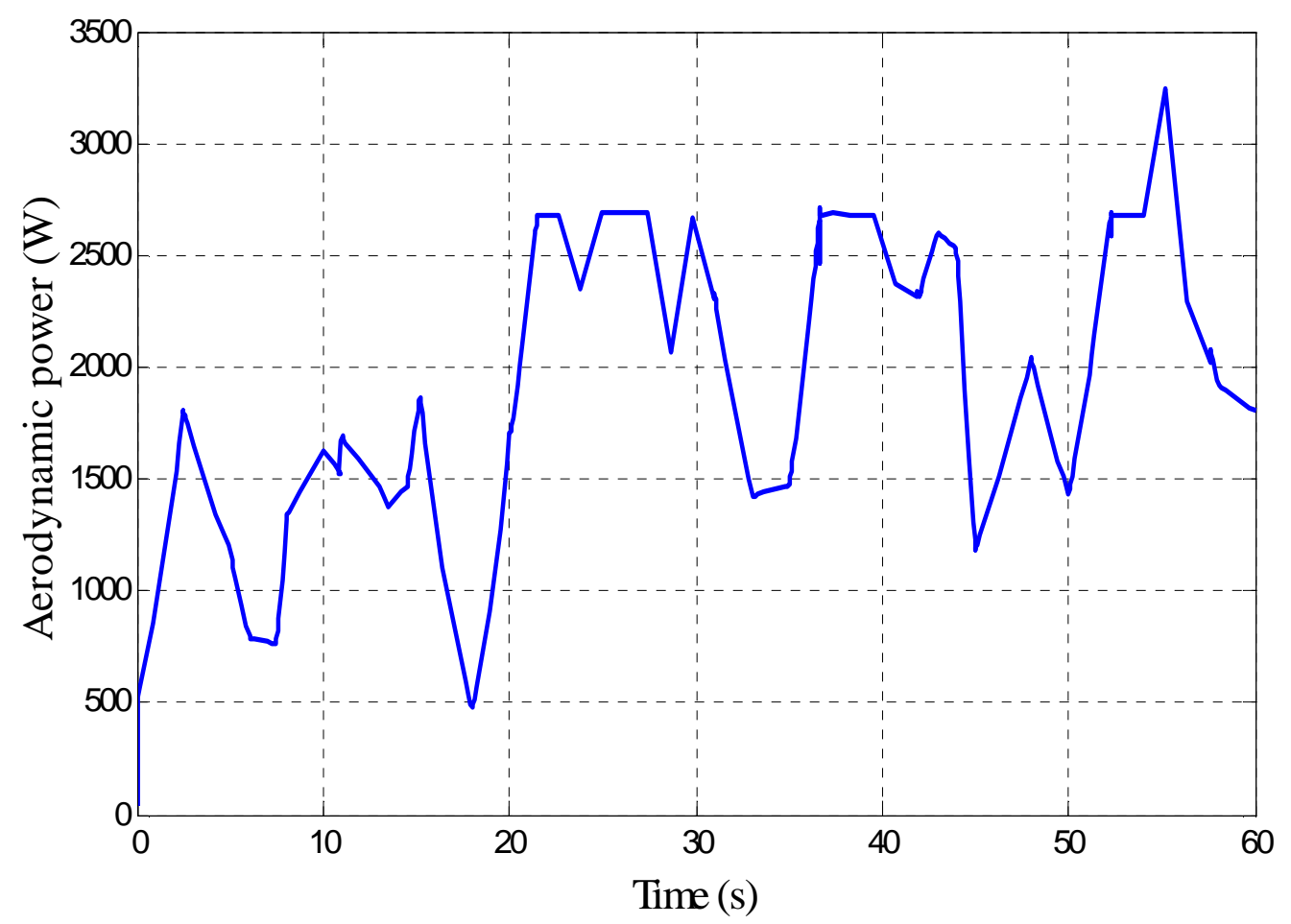

Fig.22. Wind power extracted by the turbine

Figure 23 shows the voltages generated by the permanent magnet synchronous generator according to the wind profile (fig. 18). Figure 24 is a zoom of these voltages. It could be seen that if the voltages are sinusoidal, their amplitudes and frequencies are not constant. This is due to the intermittent nature of wind.

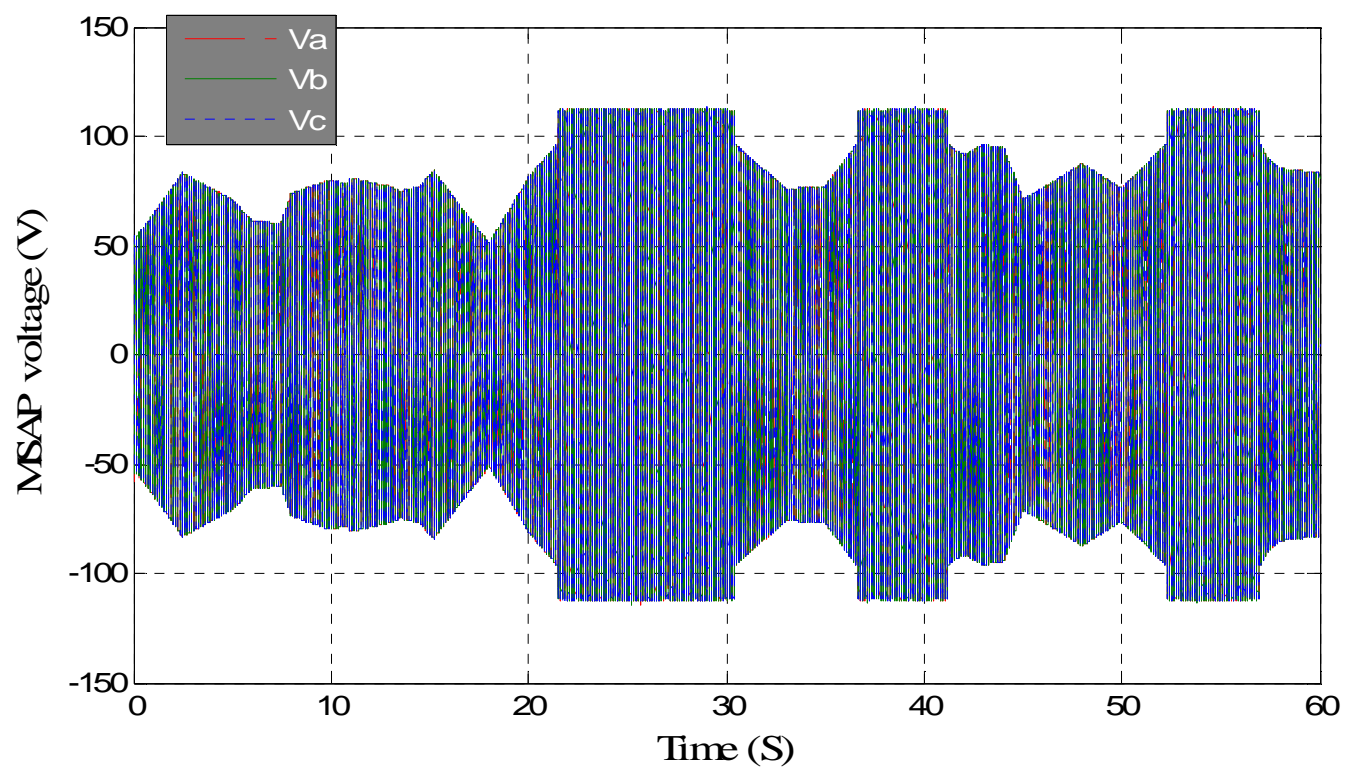

Fig.23. Voltages generated by the PMSG 


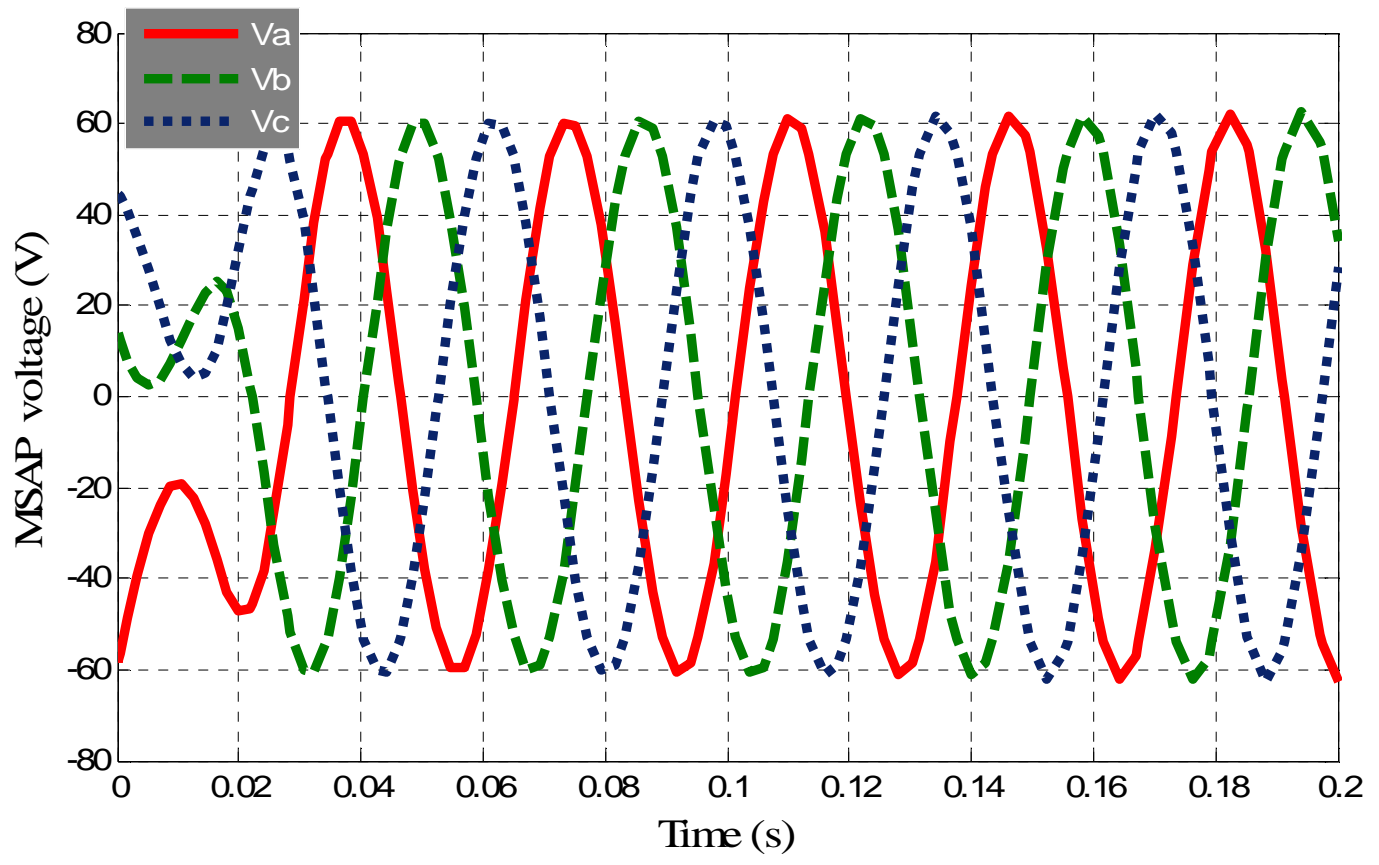

Fig.24. Zoom of voltages generated by the PMSG

Figure 26 shows that the DC bus voltage is constant at a value of $400 \mathrm{~V}$, despite variations in the rectified voltage (Figure 25) related to those of the wind. The stored energy in supercapacitors has indeed compensate for these variations through a control strategy applied to the DC bus, whose efficiency helps to fight against voltage dips and thus improve the quality of energy. The constancy of the DC bus voltage is required for the permanent supply of the load through the connection interface

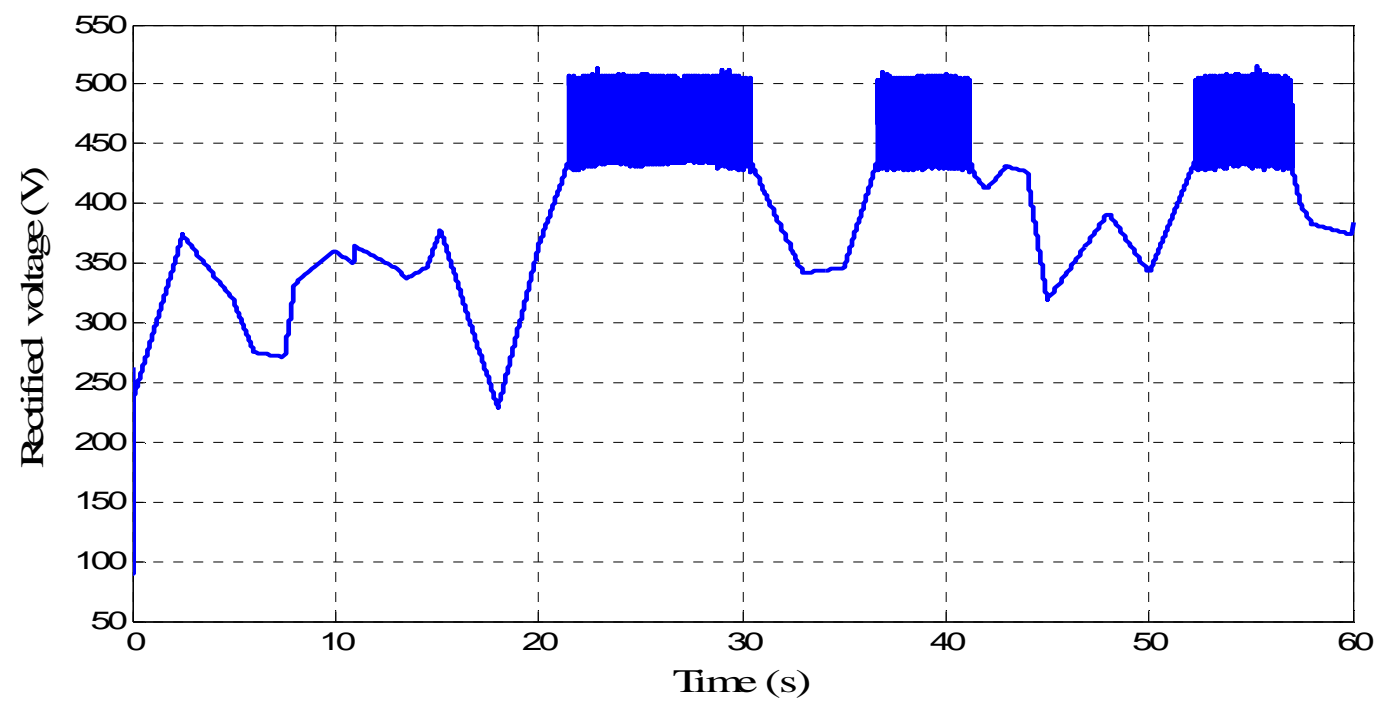

Fig.25. Voltage at the output of rectifier 


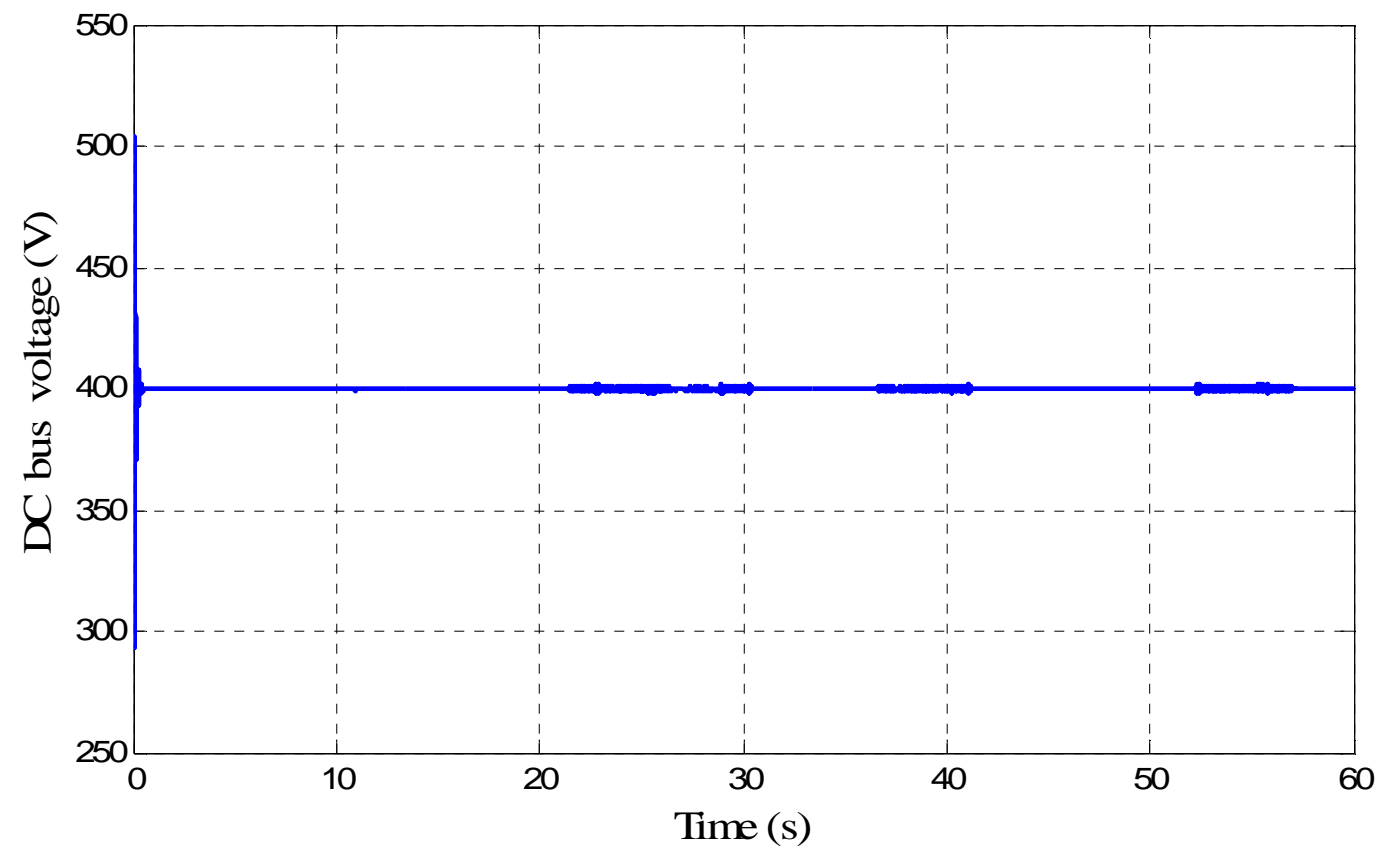

Fig.26. Voltage across the DC bus

Figures 27 and 28 shows the voltages at the output of the PWM controlled inverter. The inverter causes harmonics, degrading the quality of electrical energy (electrical wave form). As it could be seen in figure 29, these harmonics will be eliminated (Figure 30) by an LC filter whose elements were carefully sized.

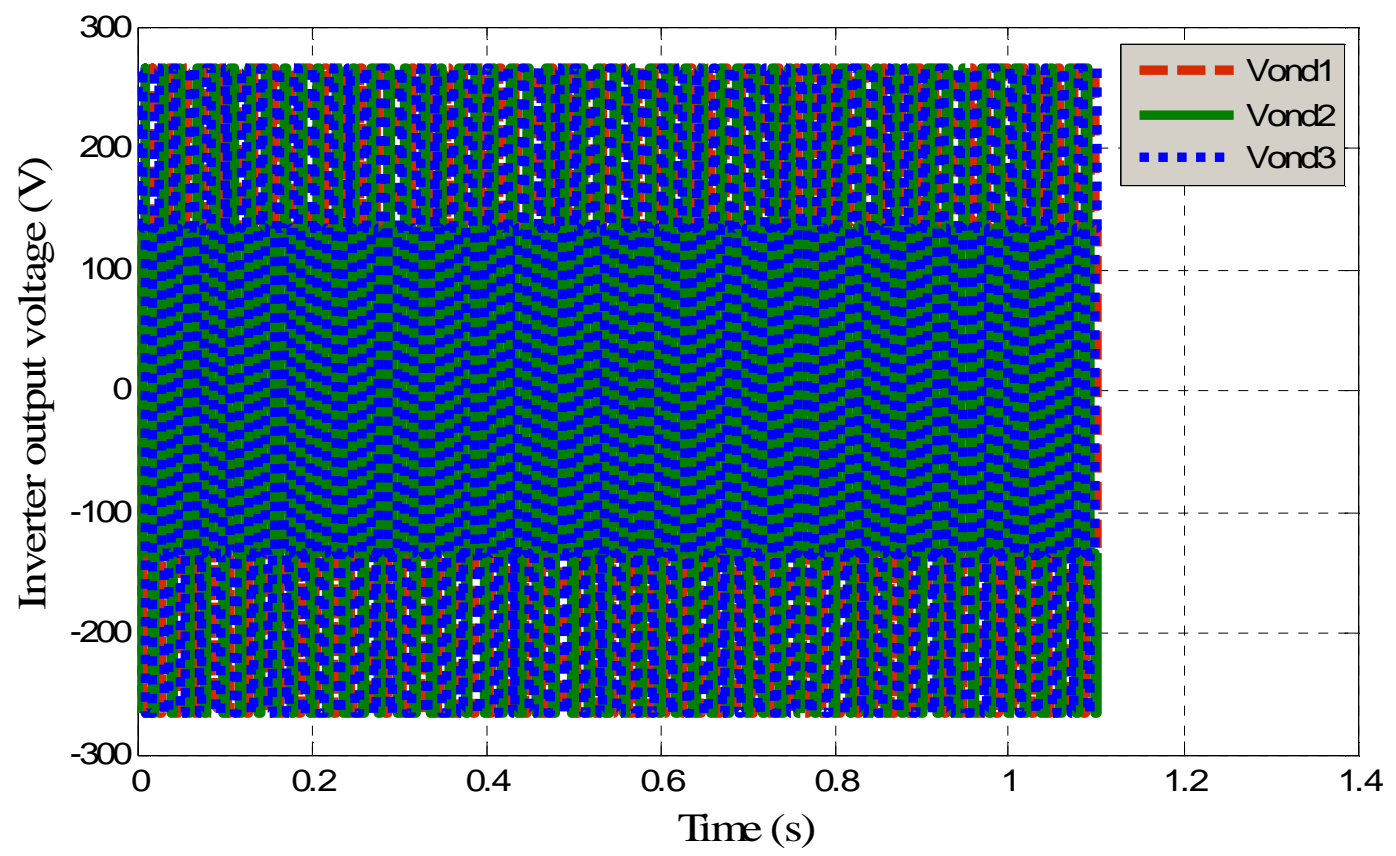

Fig.27. Voltage at the output of the inverter 


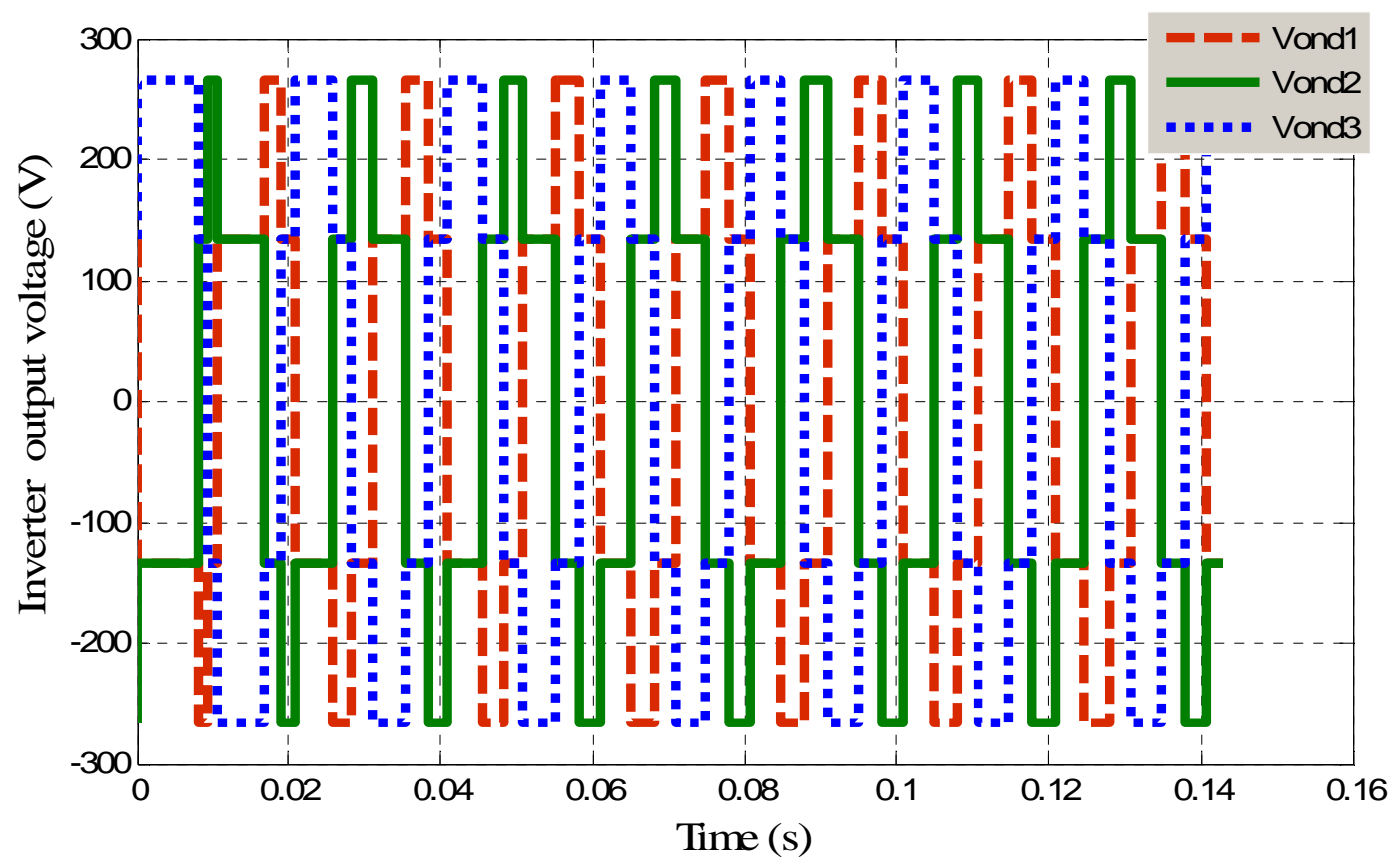

Fig.28. Zoom to the output voltages of the inverter

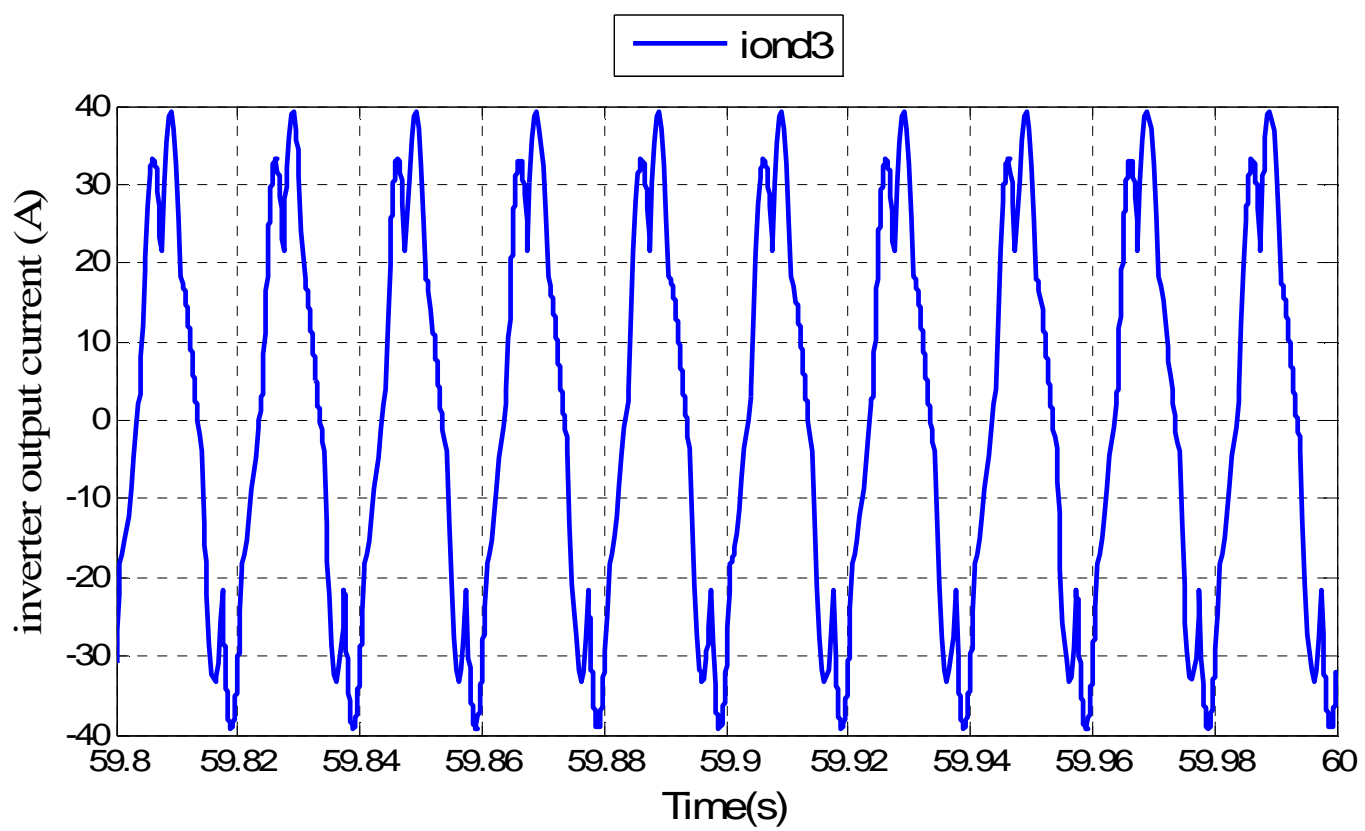

Fig.29. Output current of the inverter 


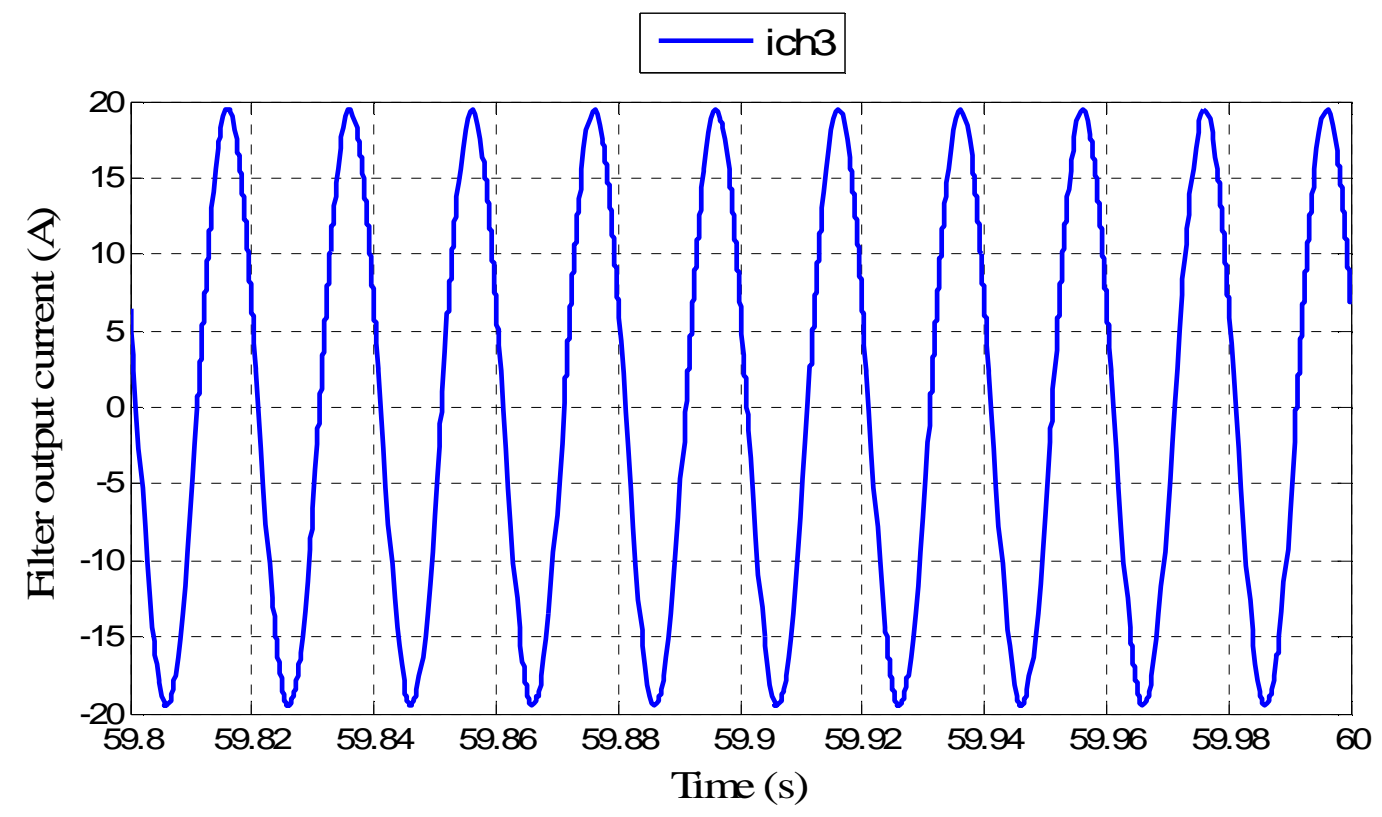

Fig.30. Output current of the LC filter

Figure 31 shows the reference voltages and fig. 32 the voltages measured at the filter outlet. It could be seen that the measured voltages are in opposition of phase to the reference voltages. The measured voltages Uc1 and Uc2 are quite stable in amplitude and frequency. They are identical to each other at an angle of phase-shift, as their respective reference. These observations could be explained by the fact that the control strategy implementation at the filter has proved its effectiveness in fighting against voltage unbalance making the power quality degrading. We also note that, even if the frequency is rather constant, the magnitudes of the measured voltages are rather higher than those of the reference voltages. The latter phenomenon is probably due to the gain regulators and indirectly, to the choice of the poles of the polynomial characteristic of the transfer functions of the filter in the closed loop. 


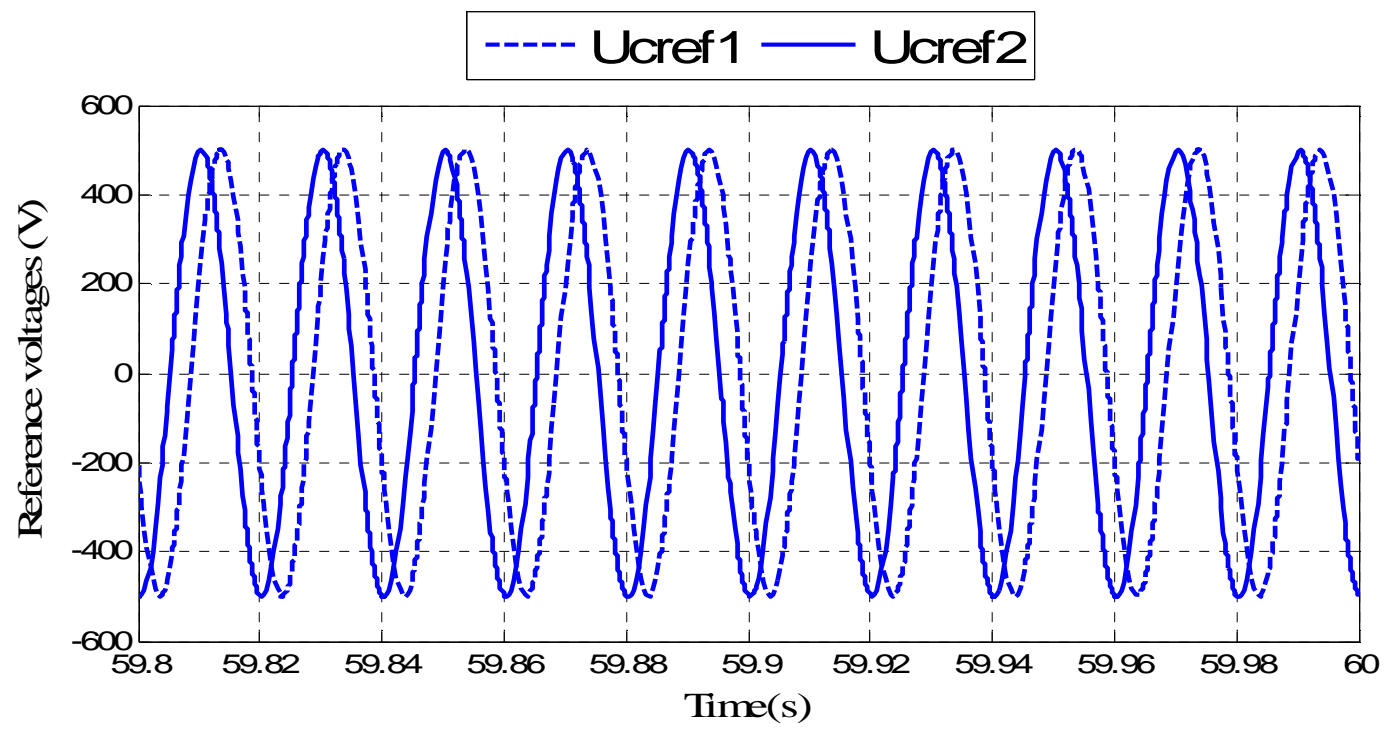

Fig.31. Reference voltages

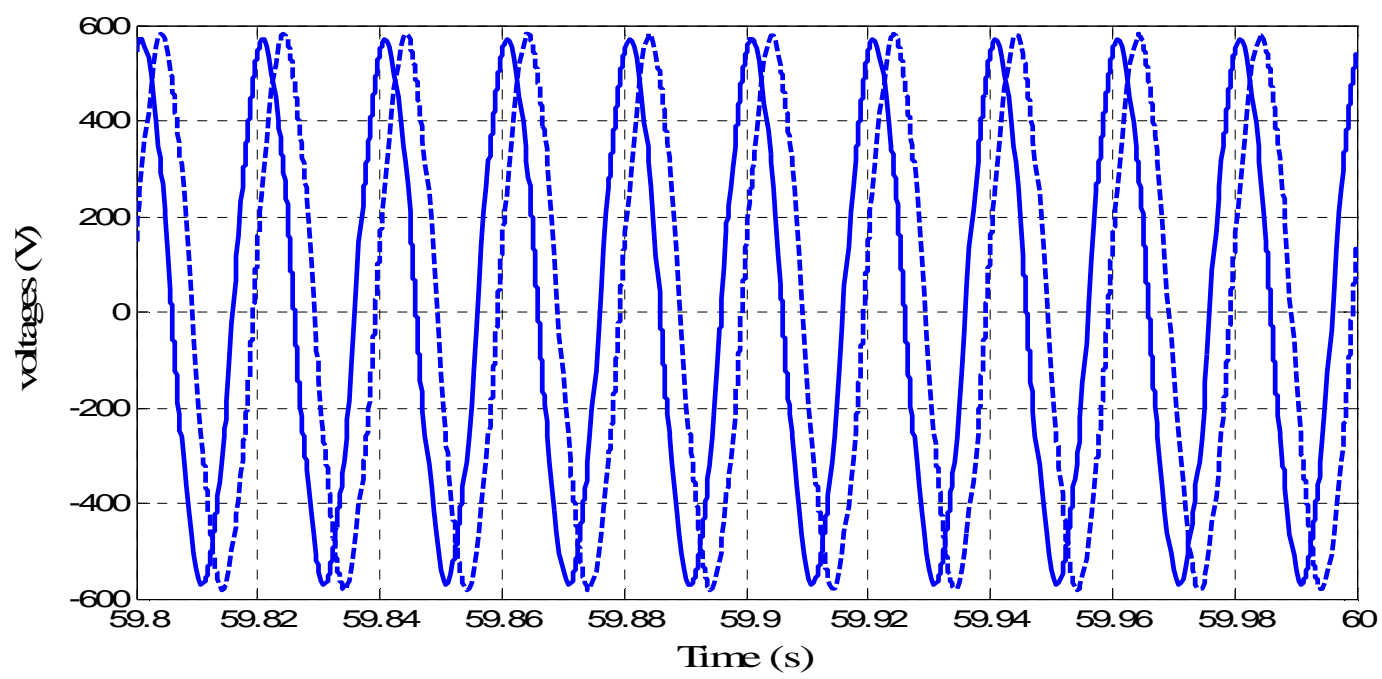

Fig.32. Measured output voltages composed filter

\section{CONCLUSION}

We modeled the parts of our system of wind energy conversion in the form of mathematical equations and block diagrams. The development of control strategies for regulating the DC bus and for the regulation of the output voltages to the LC filter has been made. Indeed, the regulation of the DC bus voltage can fight against intermittent energy production, while regulating voltages through correction proportional across the LC resonant whose elements are strictly sized filter, helps to fight against imbalances and harmonics caused by unevenly 
nonlinear distributed loads. The results obtained after simulation in Matlab-Simulink environment, demonstrate the importance and effectiveness of control strategies implemented. The voltage at the DC bus is almost constant and the voltages at the output of the filter fit their respective reference, which proves that imbalances voltages, harmonics, voltage dips and voltage fluctuations, degrading the quality of the electrical energy produced were minimized.

\section{REFERENCES}

[1] Kapseu C., Djongyang N., Nkeng G.E., Petsoko M., Egbe D.A.M. Energies renouvelables en Afrique Subsaharienne. Harmattan, 2012, 370 pages.

[2] Mons L. Les enjeux de l'énergie. Larousse, 2005.

[3] Twidel J., Weir T. Renewable Energy Resources. London \& New York: Taylor \& Francis, 2006.

[4] Laverdure N. Sur l'intégration des générateurs éoliens dans les réseaux faibles ou insulaires. Thèse de Doctorat d'institut national polytechnique de Grenoble, 2005.

[5] Courtecuisse V. Supervision d'une centrale multi sources à base d'éoliennes et de stockage d'énergie connectée au réseau électrique. Thèse de doctorat de l'école nationale des Arts et Métiers de Paris, 2007.

[6] Vechui I. Modélisation et analyse de l'intégration des énergies renouvelables dans un réseau autonome. Thèse de doctorat de l'Université du Havre, 2005.

[7] Camblong H. Minimisation de l'impact des perturbations d'origine éolienne dans la génération d'électricité par des aérogénérateurs à vitesse variable. Thèse de doctorat, l’Ecole Nationale des Arts et Métiers de Bordeaux, 2003.

[8] Davigny A. Participation aux services systèmes de fermes d'éoliennes à vitesse variable intégrant du stockage inertiel d'énergie. Thèse de Doctorat de l'Université des Sciences et Technologies de Lille, 2007.

[9] Masmoudi A., Abdelkafi A., Krichen L. Electric power generation based on variable speed wind turbine under load disturbance. Energy 2011, 36, 5016-5026.

[10] Belakehal S. Conception et Commande des Machines à Aimants Permanents Dédiées aux Energies Renouvelables. Thèse de Doctorat de l'Université de Constantine, 2010.

[11] Cecati C., Dellaquila A., Liserre M., Monopoli V. Design of H bridge multilevel active 
rectifier for traction systems. IEEE Transactions on Industry Applications 2003, 39 (5), $1541-1550$.

[12] Kazmierkowski M., Krishnan R., Blaabjerg G. Control in Power Electronics. Academie Press Series in Engineering London, 2002.

[13] Zmood D., Holmes D., Bode G. Frequency Domain Analysis of Three-Phase Linear Current Regulators. IEEE Transactions on Industry Applications 2001, 37 (2), 601-610.

How to cite this article:

Menga F.D, Djongyang N, Danwé R, Tchinda R and Zaatri A. A strategy to improve the quality of the electric power produced by a wind turbine under variable speed using a proportional resonant controller. J. Fundam. Appl. Sci., 2016, 8(2), 182-207. 